\title{
Religião, religiosidade e iniciação sexual na adolescência e juventude: lições de uma revisão bibliográfica sistemática de mais de meio século de pesquisas
}

\author{
Raquel Zanatta Coutinho* \\ Paula Miranda-Ribeiro*
}

\begin{abstract}
Apesar de ainda pouco estudada no Brasil, a influência da religião na sexualidade tem sido investigada pela literatura internacional por mais de meio século. Na literatura brasileira, a religião enquanto variável de interesse demográfico, com impacto no comportamento sexual, vem ganhando importância à medida que se fazem presentes, na sociedade, as mudanças no panorama religioso e nas normas e valores associados à sexualidade. Diante do crescente interesse, por parte dos demógrafos, na variável religião, tornam-se necessários mais subsídios teóricos com a finalidade de dar suporte às futuras pesquisas e estudos brasileiros. O presente trabalho busca, então, mapear as literaturas nacional e internacional acerca da associação entre religião, religiosidade e iniciação sexual de adolescentes e jovens e revelar as muitas formas utilizadas ao longo dos anos para classificar religião e religiosidade. Esta análise também procura ressaltar os cuidados metodológicos que devem ser tomados em estudos de sexualidade adolescente e de religião em geral. Para cumprir com esses dois objetivos, foi realizada uma revisão bibliográfica sistemática nas bases de dados SciELO, Atla, JSTOR e Banco de Teses e Dissertações do Cedeplar e da UFMG, buscando artigos publicados entre 1950 e abril de 2014, em português e inglês.
\end{abstract}

Palavras-chave: Iniciação sexual. Religião. Religiosidade. Adolescência. Revisão bibliográfica sistemática.

\footnotetext{
*Universidade da Carolina do Norte, Chapel Hill, Estados Unidos (raquelzc@live.unc.edu).

** Universidade Federal de Minas Gerais - UFMG, Belo Horizonte-MG, Brasil (paula@cedeplar.ufmg.br).
} 


\section{Introdução}

Apesar de sempre frequente nos estudos estrangeiros, o uso da religião enquanto variável demográfica, com impacto no comportamento sexual, só vem ganhando importância na literatura brasileira à medida que duas transformações se fazem presentes na sociedade brasileira. A primeira diz respeito ao panorama religioso, que se diversificou em termos de afiliações religiosas. Segundo dados dos censos demográficos, houve importante redução na proporção de pessoas autodeclaradas católicas, passando de 95\%, em 1940, para $64,6 \%$, em 2010, enquanto a proporção de protestantes aumentou de 3\% para 22,2\%, no mesmo período. Já os que se denominam sem religião passaram de menos de $1 \%$ para $8 \%$ do total (MARIANO, 2004; COSTA et al., 2005; MCKINNON et al., 2008; ALVES; NOVELLINO, 2006; IBGE, 2012). Há uma grande diversidade regional das afiliações religiosas que merece destaque. Enquanto no Nordeste 72,2\% da população se declarava católica em 2010, no Sudeste e no Centro-Oeste esta porcentagem era de apenas 59,5\% e 59,6\%, respectivamente. Em termos de Estados, o Rio de Janeiro possuía a menor proporção de católicos (45,8\%) e a maior de declarados sem-religião (15,6\%), enquanto o Piauí era o Estado com mais católicos no Brasil (85,1\%). Se a unidade de análise for a Região Metropolitana do Rio de Janeiro (RMRJ), excluindo-se a cidade do Rio de Janeiro, a proporção de católicos, em 2010, era de apenas 38,7\% (ALVES et al., 2012).

A segunda transformação foi que o Brasil, assim como outros países da América Latina, enfrentou mudanças nas suas normas e valores relacionados à sexualidade, como, por exemplo, a desvinculação da atividade sexual do casamento e reprodução. A sexualidade pré-conjugal, que de certa maneira sempre foi permitida e incentivada entre os homens, passa a ser, também, um direito da mulher (HEILBORN et al., 2006), que começa a exercêlo em idades cada vez mais jovens. Os dados da Pesquisa Nacional de Demografia e Saúde da Criança e da Mulher - PNDS de 2006 indicam que 55,2\% das jovens de 15 a 19 anos já haviam tido a primeira relação sexual, porcentagem muito mais elevada que a registrada na PNDS de 1996 (32,8\%). Já a idade mediana à primeira relação sexual diminuiu de 19,5 anos para 17 anos, entre 1996 e 2006 (BEMFAM, 1996; BRASIL, 2006).

Ao mesmo tempo, o Brasil vem assistindo a uma rápida queda na sua taxa de fecundidade total (TFT), visto que o número médio de filhos por mulher passou de 6,3, em 1960, para 1,86, em 2010. Houve, ainda, uma clara mudança no padrão da curva da fecundidade, ${ }^{1}$ que se tornou mais jovem, com as mulheres encerrando sua parturição na primeira metade do seu período reprodutivo. Assim, as taxas específicas de fecundidade (TEF) na adolescência (15-19 anos) e na fase adulta jovem (20-24 anos) ganharam importância à medida que aumentavam gradativamente sua participação relativa na TFT (BERQUÓ; CAVENAGHI, 2005; LEITE et al., 2004; COSTA et al., 2005; MCKINNON et al., 2008).

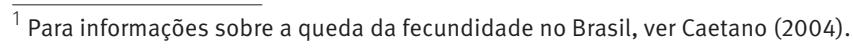


A influência da religião e da religiosidade na fecundidade das adolescentes brasileiras vem sendo documentada em vários estudos. Ogland et al. (2011), por exemplo, sugerem que, em 2006, as adolescentes com alguma filiação religiosa tinham menor chance de ter um filho na adolescência do que aquelas sem filiação religiosa. Verona e Dias Júnior (2012), ao compararem 1996 e 2006, também verificaram forte associação entre fecundidade prémarital na adolescência e envolvimento religioso nos dois anos estudados. Já McKinnon et al. (2008) mostram que a maioria das protestantes brasileiras tem menor chance de ter filhos na adolescência se comparadas às católicas, sugerindo que as igrejas protestantes parecem ser mais eficientes em desencorajar o sexo pré-marital.

No que tange ao início da vida sexual, apesar de o catolicismo e o protestantismo serem contra o sexo pré-marital, há indícios de que o segundo seja mais influente no comportamento dos jovens fiéis, justamente por enfatizar palavras fortes como castidade, virgindade e pecado (CHESNUT, 1997). Ogland et al. (2011), por exemplo, mostram que as adolescentes que se declaram protestantes e, em particular, pentecostais e aquelas com maior frequência às cerimônias religiosas têm chance maior de se manterem virgens devido ao compromisso de não ter relações sexuais antes do casamento. A tradição católica brasileira, por sua vez, foi sendo modificada e adquiriu caráter polissêmico, o que possibilitou que pessoas pertencentes à mesma denominação religiosa não possuíssem, necessariamente, unidade na vivência (BRANDÃO, 2004). De qualquer forma, as rígidas doutrinas religiosas criam a expectativa de que pessoas seguidoras dessas religiões terão posturas igualmente restritivas com relação ao sexo pré-marital, da mesma forma que os não religiosos ou sem religião serão mais liberais. Logo, é também de se esperar que o grau de conservadorismo seja diretamente proporcional à intensidade da religiosidade, não apenas da denominação religiosa.

A possível influência da religião no conhecimento, atitudes e práticas relacionadas à saúde sexual e reprodutiva reforça a necessidade de se devotar mais esforço científico com relação às variáveis de religião. Diante da demanda de aporte teórico para balizar futuros trabalhos, é preciso pesquisar a fundo o que tem sido feito ao longo dos anos em estudos de religião, religiosidade e iniciação sexual de adolescentes e jovens, entendidos aqui como os grupos etários de 15 a 19 anos e 20 a 29 anos, respectivamente. ${ }^{2}$ Assim, esse artigo pretende mapear, por meio de uma revisão bibliográfica sistemática (RBS), os principais resultados encontrados nas literaturas nacional e internacional acerca do tema, publicados entre 1950 e abril de 2014. Além disso, pretende-se fornecer insumos para orientar o desenho de questionários e roteiros de entrevistas e grupos focais, a coleta de dados, a análise das informações e a interpretação padronizada do que sejam religião e religiosidade, a fim de otimizar as análises e reduzir vieses metodológicos.

\footnotetext{
$\overline{2}$ Apesar da intenção de pesquisar apenas artigos que abordassem adolescentes, para muitas pesquisas, principalmente as internacionais, o interesse tambem está em pesquisar relações pré-maritais, que não necessariamente acontecem na adolescência. Assim, foram incluídos também os jovens.
} 
A seguir, são discutidos os antecedentes e é feito um detalhamento da metodologia da revisão bibliográfica sistemática, que resultou em 71 artigos. Posteriomente, são listadas as diversas formas de classificação observadas para religião e religiosidade e mostrados os principais resultados encontrados na RBS. Finalmente, apresenta-se um levantamento de cuidados metodológicos que devem ser tomados em estudos de religião, religiosidade e sexualidade, especialmente em se tratando de adolescentes.

\section{Antecedentes}

Após a Conferência de População de Bucareste, em 1974, vários estudos sobre sexualidade começaram a tomar forma (ODIMEGWU, 2005). Especialmente após os anos 1980, a sexualidade dos jovens ganhou muito destaque, sempre abordando o risco da Aids e da gravidez na adolescência (RIOS et al., 2008). O debate sobre iniciação sexual na adolescência fez aflorar pesquisas nas mais diversas áreas científicas, como as ciências médicas e sociais. Muito é pesquisado sobre as suas possíveis consequências, sendo a principal delas a gravidez, tratada muitas vezes como "problema social". Ser mãe na adolescência tem sido relacionado com atrasos educacionais, gravidezes de alto risco, atrasos na procura de exames pré-natais, abortos espontâneos, prematuridade e baixo peso do bebê, que podem levar ao aumento da mortalidade infantil e materna (CAMARANO, 1998; SOUZA, 1998).

Na busca por fatores associados à iniciação sexual, há uma diversidade de variáveis que agem de modo a influenciar o jovem nas suas decisões e reduzir os eventuais custos associados com a perda da virgindade (BILLY et al., 1994). Fatores como urbanização, exposição à mídia de massa, secularização, assim como o adiamento do casamento e a falta de supervisão dos filhos, levaram a um aumento da permissividade sexual entre os jovens, culminando na redução da idade na primeira relação sexual, que, por sua vez, se tornou majoritariamente pré-marital (ADDAl, 2000).

Independentemente do conjunto de fatores, a questão se agrava entre jovens de baixa renda, com alto risco social, vivendo em municípios urbanos com baixo Índice de Desenvolvimento Humano (IDH), elevados índices de criminalidade e altas taxas de evasão e repetência escolar. Estudo realizado em três comunidades, no final dos anos 1990, revela que, entre as adolescentes de menor status socioeconômico, as gravidezes geralmente ocorriam logo após o início da vida sexual e eram, em sua maioria, não planejadas. Nestas comunidades, a religião (católica e protestante) parece ter sido um dos poucos mecanismos institucionais capazes de deter o avanço das gravidezes precoces (MIRANDA-RIBEIRO; POTTER, 2010). Já os grupos religiosos em favelas no Rio de Janeiro costumam adaptar os códigos morais tradicionais, que proíbem a gravidez pré-marital, à realidade local, a fim de acolher as jovens que engravidam fora da união (STEELE, 2010).

Desde o primeiro estudo sobre sexualidade feminina, publicado em 1953, a religião já era considerada uma variável possivelmente associada à iniciação sexual pré-marital (KINSEY et al., 1953). Mais tarde, em uma revisão da literatura sobre adolescência e comportamento sexual 
publicada entre 1980 e 2000, verificou-se que a religiosidade foi consistentemente associada ao adiamento da atividade sexual, de forma que, quanto maior sua influência, maior o tempo de adiamento (WHITEHEAD et al., 2001). Mas como a religião afeta o comportamento dos indivíduos em geral e o comportamento sexual dos adolescentes em particular? Verona (2011), a partir de uma leitura do arcabouço proposto por Smith (2003), argumenta que a religião tem efeitos diretos e indiretos sobre os adolescentes. Nove fatores operam sobre o comportamento sexual, divididos em três grandes grupos: ordem moral; competências aprendidas; e laços sociais e organizacionais. A ordem moral compreende tradições que promovem ideias sobre o que é bom ou ruim, certo ou errado, justo ou injusto, entre outros, de forma a orientar a consciência humana e motivar a ação dos indivíduos. Ela atua por meio de diretivas morais, experiências espirituais e modelos a serem seguidos ("role models"). As competências aprendidas, por sua vez, compreendem habilidades e conhecimentos que melhoram o bem-estar dos indivíduos e suas chances de vida futura - as habilidades de liderança, as habilidades para lidar com perdas e o capital cultural. Finalmente, os laços sociais e organizacionais, definidos como as estruturas de relações que afetam as oportunidades e restrições dos indivíduos, operam a partir do capital social, das redes de apoio na comunidade religiosa e das habilidades fora da comunidade. Portanto, a influência da religião pode ser vista como uma força inibidora de certos comportamentos, inclusive o sexual, contribuindo para adiá-los, reduzi-los ou mesmo restringi-los, de forma direta ou indireta.

\section{Metodologia da revisão bibliográfica sistemática}

A metodologia da RBS está dividida em quatro fases: estratégia de busca; critérios de inclusão e exclusão; leitura e fichamento; e análise e escrita da revisão.

\section{Fase 1: Estratégia de busca}

A revisão bibliográfica sistemática, realizada entre julho e agosto de 2010 e atualizada em abril de 2014, ${ }^{3}$ englobou as bases de dados Journal Store (JSTOR) 4 , Scientific Electronic Library Online (SciELO), American Theological Library Association (Atla), Banco de Teses e Dissertações do Cedeplar ${ }^{5}$ e Banco de Teses e Dissertações da UFMG, ${ }^{6}$ As buscas foram feitas

\footnotetext{
$\overline{3}$ A atualização da revisão foi feita utilizando-se os mesmos critérios adotados na busca por artigos em 2010. No entanto, o período investigado nessa nova procura foi entre 2010 e 2014. Enquanto a busca de 2010 totalizou 55 artigos, a atualização da pesquisa resultou em mais 16 artigos.

${ }^{4}$ Somente após a elaboração do artigo, quando percebeu-se que o número de artigos publicados em 2013 e 2014 encontrado na base JSTOR era muito reduzido, soube-se que a JSTOR é uma base de armazenamento e por isso não inclui artigos muito recentes.

${ }^{5}$ Os resultados da busca no Banco de Teses e Dissertações da UFMG e Cedeplar foram agrupados, visto que a base do Cedeplar está contida na da UFMG.

${ }^{6}$ Durante a busca em 2010, percebeu-se o mal funcionamento da ferramenta de busca do Banco de Teses e Dissertações da UFMG, que retornava, sem variação, os 1.554 resultados. A solução encontrada foi abrir cada um dos documentos, lendo seus títulos, palavras-chave e resumos, de forma a salvar apenas os que tinham interesse de pesquisa. Por serem muitos textos, optou-se por não proceder à leitura do corpo do texto em todos os 1.554 artigos, mas as palavras-chave eram procuradas no corpo do texto, caso o resumo não esclarecesse os objetivos do artigo.
} 
diretamente nos portais eletrônicos em questão, utilizando chave de acesso para chegar aos textos completos em formato PDF e limitando o período de busca para aqueles publicados entre 1950 e 2014. No presente trabalho, para fins de simplificação, dissertações e teses também serão chamadas de artigos.

Na estratégia de busca para obtenção de artigos em inglês, foram empregadas as seguintes palavras-chave: ((adolescence or adolescent or teenagers) AND (sexual initiation or sexual debut or first time or first sexual intercourse) AND (religion or religiosity)). No processo de busca para a captura de artigos em português, utilizaram-se as palavraschave: ((adolescência ou adolescente) E (iniciação sexual ou primeira vez ou primeira relação sexual) E (religião ou religiosidade)). Apesar de a palavra juventude ter sido usada na busca por palavras em português, ela não foi essencial na procura, haja vista que uma nova pesquisa sem a palavra mostrou os mesmos resultados encontrados. Os critérios de busca foram aplicados para títulos, resumos, palavras-chave e corpo do texto. Optou-se por não contemplar artigos cujo objeto de pesquisa fosse composto exclusivamente por membros da religião muçulmana e judaica, uma vez que a presença das mesmas no Brasil é pouco significante.

Para as bases de dados SciELO, JSTOR, UFMG e Cedeplar, foram excluídas as referências que não continham o artigo completo em PDF, uma vez que, no momento da consulta, era possivel observar a inexistência do arquivo completo. Já para a base de dados Atla, todas as referências foram mantidas durante essa primeira fase de busca, pois a verificação da existência de PDF demandaria longo tempo adicional nesta fase da coleta.

Nesta primeira fase, foram encontradas 406 referências de trabalhos, sendo 21 no Banco de Teses e Dissertações da UFMG e Cedeplar, 43 na SciELO, 170 no JSTOR e 172 no Atla.

\section{Fase 2: Critérios de inclusão e exclusão}

Na segunda fase, todas as 406 referências foram reavaliadas. Destas, excluíram-se aquelas que não cumpriam todos os critérios estabelecidos para a RBS: artigo científico; texto completo disponível em PDF; iniciação sexual como tema principal e religião como variável de interesse ou variável de controle.

Primeiramente, fazia-se o download do PDF, que era salvo e aberto. Caso ele não estivesse disponível, a referência era excluída. Em seguida, eram lidos, nesta ordem, o título do trabalho, as palavras-chave, o resumo e, se necessário, parte do corpo do texto. Se o título já indicasse se tratar de um artigo que objetivasse estudar a iniciação sexual, procedia-se à procura da variável de religião. Caso a mesma fosse encontrada, o texto era mantido; caso contrário, o texto era excluído. O box Fase 2 da Figura 1 mostra o fluxograma completo do processo de exclusão.

Após essa segunda fase, foram selecionados cinco dissertações ou teses da UFMG e Cedeplar, 23 artigos da SciELO, 59 do JSTOR e 12 do Atla, somando 99 referências. 
FIGURA 1

Apresentação esquemática dos artigos incluídos e excluídos na revisão sistemática, Fases 1, 2 e 3

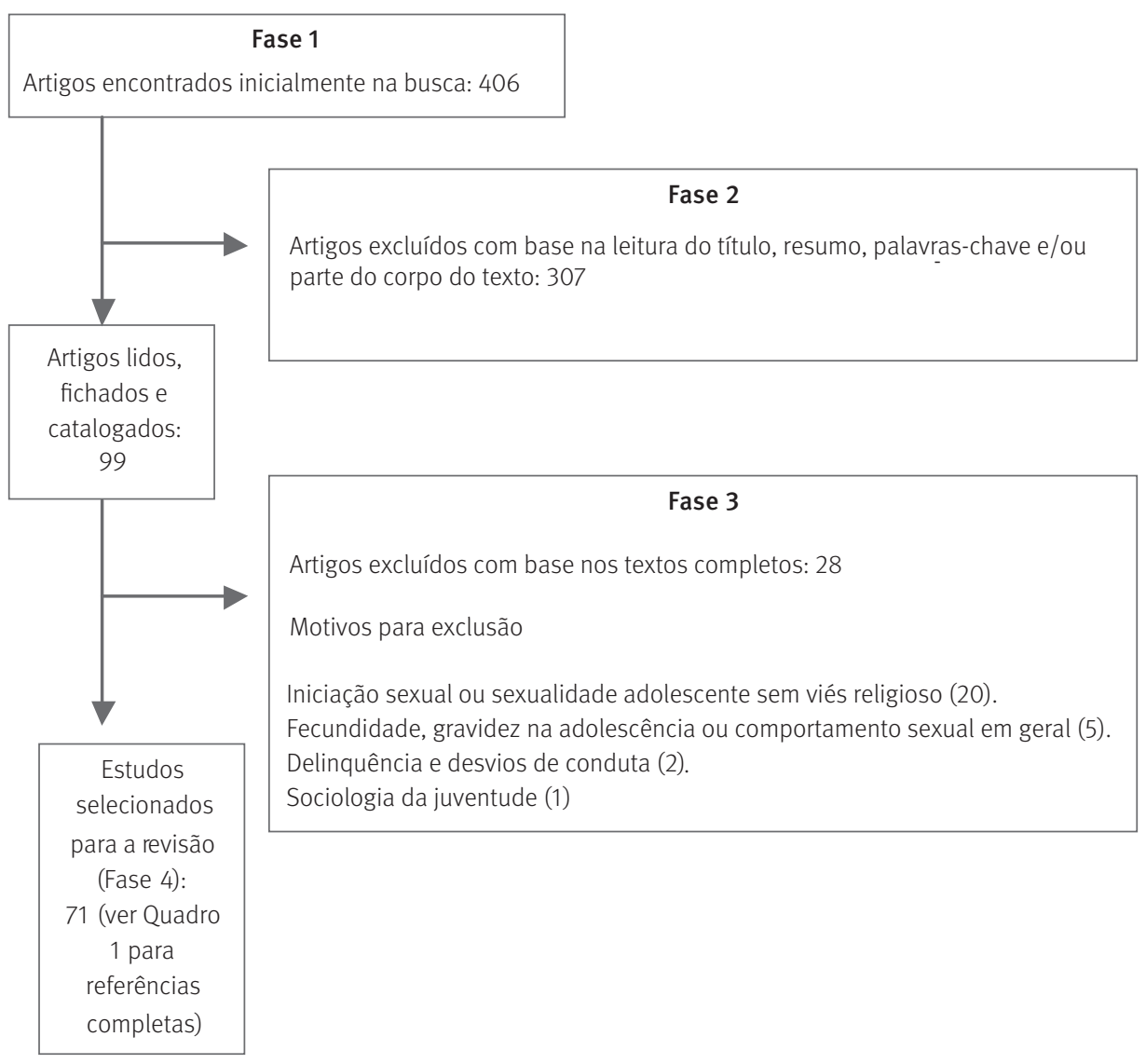

\section{Fase 3: Leitura e fichamento}

A terceira fase incluiu a leitura dos 99 textos selecionados e a coleta das informações necessárias à RBS. Estas informações foram armazenadas em uma planilha do programa Microsoft Excel, de acordo com as seguintes variáveis: 1. Autores; 2. Ano; 3. Objetivos; 4. Descrição da amostra; 5. Metodologia; 6. Resultados. Os artigos puramente teóricos, sem testes empíricos, foram fichados e digitados no programa Microsoft Excel, de acordo com as seguintes variáveis: 1 . Autores; 2 . Ano; 3. Pontos importantes citados por outros autores; 4. Pontos importantes citados pelo artigo.

Nessa fase, mesmo os artigos que porventura se distanciassem do objetivo da pesquisa eram fichados e catalogados, já que muitos só se mostravam desviantes do assunto na ocasião da leitura da metodologia ou dos resultados. 


\section{Fase 4: Análise e escrita da revisão}

A última etapa consistiu na análise dos achados da revisão sistemática. Os arquivos que não contemplavam o objeto central da pesquisa - a associação entre religião, religiosidade e iniciação sexual na adolescência - não foram considerados. Assim, foram eliminados 28 textos, resultando em 71 documentos que foram analisados (Quadro 1).

QUADRO 1

Descrição dos artigos analisados na última etapa da revisão sistemática

\begin{tabular}{|c|c|c|c|c|c|c|c|}
\hline Autores & Ano & País & $\begin{array}{l}\text { Natureza } \\
\text { principal }\end{array}$ & $\begin{array}{c}\text { Base de } \\
\text { dados }\end{array}$ & Sexo & Metodologia ou método & $\begin{array}{c}\text { Amostra } \\
\text { (n. ou idade) }\end{array}$ \\
\hline Landis & 1960 & EUA & Empírico & Própria & FM & $\begin{array}{l}\text { Quantitativa descritiva } \\
\text { (teste de associação pelo } \\
\text { qui-quadrado) }\end{array}$ & 2.654; universitários \\
\hline Glass & 1972 & EUA & Empírico & Própria & FM & Quantitativa descritiva & 301; ensino médio \\
\hline $\begin{array}{l}\text { Henze e } \\
\text { Hudson }\end{array}$ & 1974 & EUA & Empírico & Própria & FM & Quantitativa descritiva & 291; universitários \\
\hline Miller e Simon & 1974 & EUA & Empírico & Própria & FM & Quantitativa descritiva & $2.064 ; 14-17$ \\
\hline Spanier & 1975 & EUA & Teórico & n.a. & n.a. & n.a. & n.a. \\
\hline Albrecht et al. & 1977 & EUA & Empírico & Própria & FM & $\begin{array}{l}\text { Correlações de Pearson } \\
\text { multivariadas }\end{array}$ & 244; adolescentes \\
\hline Murray & 1978 & $\begin{array}{l}\text { Reino } \\
\text { Unido }\end{array}$ & Empírico & Própria & FM & $\begin{array}{l}\text { Análise multivariada de } \\
\text { componentes e de médias } \\
\text { recíprocas e matriz de } \\
\text { correlação }\end{array}$ & $\begin{array}{l}\text { 1.284; moda } 14 \\
\text { anos }\end{array}$ \\
\hline Mahoney & 1980 & EUA & Empírico & Própria & FM & $\begin{array}{l}\text { Correlações de ordem zero, } \\
\text { testes para diferenças } \\
\text { entre médias e proporções }\end{array}$ & 441; universitários \\
\hline Woodroof & 1985 & EUA & Empírico & Própria & FM & $\begin{array}{l}\text { Regressão linear, one-way } \\
\text { ANOVA }\end{array}$ & $477 ; 17-19$ \\
\hline Thornton & 1985 & EUA & Teórico & n.a. & n.a. & n.a. & n.a. \\
\hline Tanfer e Horn & 1985 & EUA & Empírico & $\begin{array}{l}1983 \text { Nat. } \\
\text { Survey of } \\
\text { Unmarried } \\
\text { Women }\end{array}$ & $\mathrm{F}$ & Quantitativa descritiva & $1.314 ; 20-29$ \\
\hline $\begin{array}{l}\text { Thornton e } \\
\text { Camburn }\end{array}$ & 1987 & EUA & Empírico & Própria & FM & $\begin{array}{l}\text { Análise multivariada, } \\
\text { coeficientes de regressão } \\
\text { padronizada }\end{array}$ & $\begin{array}{l}\text { 916; jovens e suas } \\
\text { mães }\end{array}$ \\
\hline Miller et al. & 1987 & EUA & Empírico & Própria & FM & $\begin{array}{l}\text { Correlações de ordem zero, } \\
\text { regressões padronizadas }\end{array}$ & $836 ; 14-19$ \\
\hline $\begin{array}{l}\text { Miller e } \\
\text { Bingham }\end{array}$ & 1989 & EUA & Empírico & $\begin{array}{l}\text { Zelnik and } \\
\text { Kantner data } \\
\text { set, } 1979\end{array}$ & $\mathrm{~F}$ & $\begin{array}{l}\text { Regressão múltipla, } \\
\text { correlações bivariadas }\end{array}$ & $1.571 ; 15-19$ \\
\hline $\begin{array}{l}\text { Shornack e } \\
\text { Ahmed }\end{array}$ & 1989 & EUA & Crítica & n.a. & n.a. & n.a. & n.a. \\
\hline $\begin{array}{l}\text { Studer e } \\
\text { Thornton }\end{array}$ & 1989 & EUA & Crítica & n.a. & n.a. & n.a. & n.a. \\
\hline Jensen et al. & 1990 & EUA & Empírico & Própria & FM & Análise de variância & $423 ; 17-25$ \\
\hline Casper & 1990 & EUA & Empírico & Própria & $\mathrm{F}$ & $\begin{array}{l}\text { Modelo de regressão } \\
\text { logística }\end{array}$ & $1.888 ; 15-19$ \\
\hline Kiragu e Zabin & 1993 & Quênia & Empírico & Própria & FM & $\begin{array}{l}\text { Regressão logística } \\
\text { múltipla, estimação de } \\
\text { razão de chance ajustada }\end{array}$ & 3.182; adolescentes \\
\hline $\begin{array}{l}\text { Hammond } \\
\text { et al. }\end{array}$ & 1993 & EUA & Empírico & NLSY, 1979 & FM & $\begin{array}{l}\text { Modelo de regressão } \\
\text { logística }\end{array}$ & $8.637,14-22$ \\
\hline Billy et al. & 1994 & EUA & Empírico & NSFG III & $\mathrm{F}$ & $\begin{array}{l}\text { Modelo de regressão } \\
\text { logística, regressão tobit }\end{array}$ & $1.852 ; 15-19$ \\
\hline Reynolds & 1994 & EUA & Crítica & n.a. & n.a. & n.a. & n.a. \\
\hline Davidson et al. & 1995 & EUA & Empírico & Própria & $\mathrm{F}$ & $\begin{array}{l}\text { Teste qui-quadrado, } \\
\text { Manova, Procedimento de } \\
\text { Tukey }\end{array}$ & 868; adultas \\
\hline
\end{tabular}


(continuação)

\begin{tabular}{|c|c|c|c|c|c|c|c|}
\hline Autores & Ano & País & $\begin{array}{l}\text { Natureza } \\
\text { principal }\end{array}$ & $\begin{array}{c}\text { Base de } \\
\text { dados }\end{array}$ & Sexo & Metodologia ou método & $\begin{array}{c}\text { Amostra } \\
\text { (n. ou idade) }\end{array}$ \\
\hline Cooksey et al. & 1996 & EUA & Empírico & NSFG III e IV & $\mathrm{F}$ & $\begin{array}{l}\text { Modelos de incidência em } \\
\text { tempo discreto, regressão } \\
\text { logística, abordagem da } \\
\text { estimação conjunta }\end{array}$ & $3.374 ; 10-19$ \\
\hline Brewster et al. & 1998 & EUA & Empírico & NSFG-III e IV & $\mathrm{F}$ & $\begin{array}{l}\text { Quantitativa descritiva, } \\
\text { estimação conjunta de } \\
\text { verossimilhança }\end{array}$ & $1.975 ; 15-23$ \\
\hline Murray et al. & 1998 & Chile & Empírico & Própria & FM & $\begin{array}{l}\text { Regressão logística } \\
\text { multivariada }\end{array}$ & $4.248 ; 11-19$ \\
\hline Fehring et al. & 1998 & EUA & Empírico & Própria & FM & $\begin{array}{l}\text { Qualitativa: entrevista. } \\
\text { Correlação produto- } \\
\text { momento e correlações } \\
\text { de Pearson, regressão } \\
\text { stepwise }\end{array}$ & $82 ; 17-21$ \\
\hline Davis e Lay-Lee & 1999 & $\begin{array}{l}\text { Nova } \\
\text { Zelândia }\end{array}$ & Empírico & $\begin{array}{l}\text { National } \\
\text { Survey of } \\
\text { Sexual } \\
\text { Lifestyle }\end{array}$ & FM & $\begin{array}{l}\text { Análise de sobrevivência, } \\
\text { regressão logística } \\
\text { múltipla, análise } \\
\text { multivariada }\end{array}$ & $2.361 ; 18-54$ \\
\hline Garner & 2000 & $\begin{array}{l}\text { África } \\
\text { do Sul }\end{array}$ & Empírico & Própria & FM & $\begin{array}{l}\text { Qualitativa: pesquisa } \\
\text { etnográfica, entrevista, } \\
\text { visitas técnicas. Análise } \\
\text { quant. descritiva }\end{array}$ & n.a. \\
\hline Gupta & 2000 & Brasil & Empírico & $\begin{array}{l}\text { DHS } 1986 \text { e } \\
\text { PNDS } 1996\end{array}$ & $\mathrm{~F}$ & $\begin{array}{l}\text { Modelos logísticos } \\
\text { multivariados estocásticos }\end{array}$ & $5.695 ; 15-24$ \\
\hline Addai & 2000 & Gana & Empírico & GDHS, 1993 & $\mathrm{~F}$ & Análise multivariada & $1.314 ; 15-49$ \\
\hline Longo & 2001 & Brasil & Empírico & $\begin{array}{l}\text { Bemfam, } \\
1996\end{array}$ & $\mathrm{~F}$ & $\begin{array}{l}\text { Modelo de regressão } \\
\text { logística }\end{array}$ & $1.715 ; 15-24$ \\
\hline $\begin{array}{l}\text { Bearman e } \\
\text { Brückner }\end{array}$ & 2001 & EUA & Empírico & $\begin{array}{l}\text { Add Health, } \\
1994 \text { a } 1996\end{array}$ & FM & $\begin{array}{l}\text { Modelos multivariados, } \\
\text { modelo estocástico de } \\
\text { taxas, estimação da função } \\
\text { de sobrevivência }\end{array}$ & $\begin{array}{l}\text { 14.787; séries } 7 \text { a } 12 \\
\text { (EUA) }\end{array}$ \\
\hline $\begin{array}{l}\text { Scheepers } \\
\text { et al. }\end{array}$ & 2002 & $\begin{array}{l}\text { Vários } \\
\text { (1) }\end{array}$ & Empírico & $\begin{array}{l}\text { ISSP-91 } \\
\text { database }\end{array}$ & FM & Análise multinível & $16.604 ; 18-75$ \\
\hline $\begin{array}{l}\text { Rowatt e } \\
\text { Schmitt }\end{array}$ & 2003 & EUA & Empírico & Própria & FM & $\begin{array}{l}\text { Quantitativa descritiva } \\
\text { (teste de associação pelo } \\
\text { qui-quadrado), regressão } \\
\text { múltipla e padronizada }\end{array}$ & $161 ;>18$ \\
\hline Smith & 2003 & EUA & Teórico & n.a. & n.a. & n.a. & n.a. \\
\hline Meier & 2003 & EUA & Empírico & $\begin{array}{l}\text { Add Health, } \\
1995 \text { e } 1996\end{array}$ & FM & $\begin{array}{l}\text { Probit ajustado por } \\
\text { máxima verossimilhança, } \\
\text { modelo de seleção de } \\
\text { Heckman, change score } \\
\text { models }\end{array}$ & $4.948 ; 15-18$ \\
\hline Rostosky et al. & 2003 & EUA & Empírico & $\begin{array}{l}\text { Add Health, } \\
1995 \text { e } 1996\end{array}$ & FM & $\begin{array}{l}\text { Análise de componentes } \\
\text { principais, análise de } \\
\text { correlação, modelo } \\
\text { logístico hierárquico }\end{array}$ & $3.691 ; 15-21$ \\
\hline Slap et al. & 2003 & Nigéria & Empírico & Própria & FM & $\begin{array}{l}\text { Modelo de regressão } \\
\text { logística }\end{array}$ & $2.705 ; 12-21$ \\
\hline Smith & 2004 & Nigéria & Empírico & Própria & FM & $\begin{array}{l}\text { Qualitativa: observação } \\
\text { participante }\end{array}$ & $863 ; 15-24$ \\
\hline Odimegwu & 2005 & Nigéria & Empírico & Própria & FM & $\begin{array}{l}\text { Modelo de regressão } \\
\text { logística }\end{array}$ & $1.153 ; 10-24$ \\
\hline $\begin{array}{l}\text { Regnerus e } \\
\text { Smith }\end{array}$ & 2005 & EUA & Empírico & $\begin{array}{l}\text { Add Health, } \\
1994 \text { e } 1995\end{array}$ & FM & $\begin{array}{l}\text { Medidas múltiplas de } \\
\text { religião, modelos de } \\
\text { mudança puros }\end{array}$ & $12.530 ; 11-20$ \\
\hline Manlove et al. & 2006 & EUA & Empírico & NSFG, 2002 & FM & $\begin{array}{l}\text { Regressão logística bi e } \\
\text { multivariada, qui-quadrado } \\
\text { bivariado, análise de } \\
\text { contraste }\end{array}$ & $1.838 ; 18-24$ \\
\hline L'Engle et al. & 2006 & EUA & Empírico & Própria & FM & $\begin{array}{l}\text { Modelo de regressão } \\
\text { logística }\end{array}$ & $854 ; 12-15$ \\
\hline
\end{tabular}


(continuação)

\begin{tabular}{|c|c|c|c|c|c|c|c|}
\hline Autores & Ano & País & $\begin{array}{l}\text { Natureza } \\
\text { principal }\end{array}$ & $\begin{array}{c}\text { Base de } \\
\text { dados }\end{array}$ & Sexo & Metodologia ou método & $\begin{array}{c}\text { Amostra } \\
\text { (n. ou idade) }\end{array}$ \\
\hline Francis & 2007 & EUA & Empírico & $\begin{array}{l}\text { Add Health, } \\
1994 \text { e } 1995\end{array}$ & FM & $\begin{array}{l}\text { Modelo de regressão } \\
\text { logística }\end{array}$ & $17.610 ; 11-21$ \\
\hline Menning et al. & 2007 & EUA & Empírico & $\begin{array}{l}\text { Add Health, } \\
1994\end{array}$ & FM & $\begin{array}{l}\text { Modelo de regressão } \\
\text { linear, regressão linear } \\
\text { ajustadas para survey, } \\
\text { logito ordenado }\end{array}$ & $923 ; 15-20$ \\
\hline França & 2008 & Brasil & Empírico & SRSR, 2002 & $\mathrm{~F}$ & $\begin{array}{l}\text { Modelos de incidência em } \\
\text { tempo discreto }\end{array}$ & $2.408,15-24$ \\
\hline $\begin{array}{l}\text { Barbosa e } \\
\text { Koyama }\end{array}$ & 2008 & Brasil & Empírico & Própria & FM & Pearson qui-quadrado & $\begin{array}{l}3.423-1998,5.040 \\
-2005 ; 16-65\end{array}$ \\
\hline Paiva et al. & 2008 & Brasil & Empírico & Própria & FM & Quantitativa descritiva & $5.040 ; 16-65$ \\
\hline Vidal e Ribeiro & 2008 & Brasil & Empírico & Própria & FM & $\begin{array}{l}\text { Qualitativa: análise de } \\
\text { conteúdo de redações } \\
\text { escritas por alunos }\end{array}$ & $255,14-19$ \\
\hline Rios et al. & 2008 & Brasil & Empírico & Própria & FM & $\begin{array}{l}\text { Qualitativa: etnografia, } \\
\text { observação, levantamento } \\
\text { documental, entrevistas. }\end{array}$ & n.a. \\
\hline Silva et al. & 2008 & Brasil & Empírico & Própria & FM & $\begin{array}{l}\text { Qualitativa: entrevistas } \\
\text { semiestruturadas }\end{array}$ & n.a. \\
\hline Burdette e Hill & 2009 & EUA & Empírico & $\begin{array}{l}\text { NSYR, } 2002 \\
\text { e } 2005\end{array}$ & FM & $\begin{array}{l}\text { Modelo de regressão } \\
\text { logística }\end{array}$ & $3.290,13-17$ \\
\hline Tavares et al. & 2009 & $\begin{array}{l}\text { Cabo } \\
\text { Verde }\end{array}$ & Empírico & Própria & FM & $\begin{array}{l}\text { Pearson's qui-quadrado, } \\
\text { Fisher's exact test e } \\
\text { modelo de regressão } \\
\text { logística }\end{array}$ & $768 ; 13-17$ \\
\hline $\begin{array}{l}\text { Nascimento e } \\
\text { Gomes }\end{array}$ & 2009 & Brasil & Empírico & Própria & $M$ & $\begin{array}{l}\text { Qualitativa: entrevistas } \\
\text { semiestruturadas }\end{array}$ & $\begin{array}{l}19,15-17 \\
\text { anos, sendo que a } \\
\text { maioria (15) tem } \\
16 \text { anos, }\end{array}$ \\
\hline Gaydos et al. & 2010 & World & Teórico & PubMed & n.a. & $\begin{array}{l}\text { Revisão sistemática da } \\
\text { literatura }\end{array}$ & n.a. \\
\hline $\begin{array}{l}\text { Haglund e } \\
\text { Fehring }\end{array}$ & 2010 & EUA & Empírico & NSFG 2002 & FM & $\begin{array}{l}\text { Chi-square, razão de } \\
\text { chances, análise de } \\
\text { sobrevivência }\end{array}$ & $3.168,15-21$ \\
\hline Baptista & 2011 & Brasil & Empírico & $\begin{array}{l}\text { Projeto } \\
\text { Saúde- } \\
\text { Escola - } \\
\text { Sexo sem } \\
\text { Grilo }\end{array}$ & FM & Pearson qui-quadrado & $775,12-22$ \\
\hline Burchardt & 2011 & $\begin{array}{l}\text { África } \\
\text { do Sul }\end{array}$ & Empírico & Própria & FM & $\begin{array}{l}\text { Observação participante, } \\
\text { grupo focal, entrevista }\end{array}$ & n.a. $(16-24)$ \\
\hline Coutinho & 2011 & Brasil & Empírico & $\begin{array}{l}\text { Pesquisa } \\
\text { Jovem }\end{array}$ & FM & $\begin{array}{l}\text { Modelo de regressão } \\
\text { logística }\end{array}$ & $2.658,15-19$ \\
\hline Crawford et al. & 2011 & Jamaica & Empírico & Própria & FM & $\begin{array}{l}\text { Qualitativa: entrevista } \\
\text { semiestruturada. } \\
\text { Quantitativa: estatística } \\
\text { descritiva }\end{array}$ & $48,15-24$ \\
\hline $\begin{array}{l}\text { Hull e } \\
\text { Hennessy }\end{array}$ & 2011 & EUA & Empírico & $\begin{array}{l}\text { Annenberg } \\
\text { Sex and } \\
\text { Media Study }\end{array}$ & FM & $\begin{array}{l}\text { Structural equation } \\
\text { modeling (SEM) }\end{array}$ & $369,14-16$ \\
\hline Hugo et al. & 2011 & Brasil & Empírico & Própria & FM & $\begin{array}{l}\text { Análise de sobrevivência } \\
\text { (regressão de Cox e } \\
\text { modelo hierárquico) }\end{array}$ & $1.621,18-24$ \\
\hline Ishida et al. & 2011 & Jamaica & Empírico & $\begin{array}{l}\text { Reproductive } \\
\text { Health } \\
\text { Survey, } \\
2008-2009\end{array}$ & & $\begin{array}{l}\text { Análise bivariada e } \\
\text { multivariada }\end{array}$ & $2.808,15-19$ \\
\hline $\begin{array}{l}\text { Marsicano } \\
\text { et al. }\end{array}$ & 2011 & França & Empírico & Própria & FM & $\begin{array}{l}\text { Pearson qui-quadrado e } \\
\text { regressão logística }\end{array}$ & 1.871 \\
\hline Stulhofer & 2011 & Croácia & Empírico & Própria & FM & $\begin{array}{l}\text { Pearson qui-quadrado, test } \\
\text { t, modelo de regressão } \\
\text { linear }\end{array}$ & $\begin{array}{l}\text { W1:1.355, W2:537, } \\
\text { W3:775 (2) }\end{array}$ \\
\hline
\end{tabular}




\begin{tabular}{|c|c|c|c|c|c|c|c|}
\hline Autores & Ano & País & $\begin{array}{l}\text { Natureza } \\
\text { principal }\end{array}$ & $\begin{array}{c}\text { Base de } \\
\text { dados }\end{array}$ & Sexo & Metodologia ou método & $\begin{array}{c}\text { Amostra } \\
\text { (n. ou idade) }\end{array}$ \\
\hline Adamczyk & 2012 & EUA & Empírico & NSYR & FM & $\begin{array}{l}\text { Modelo de regressão } \\
\text { logística multinomial }\end{array}$ & $2.013,13-17$ \\
\hline $\begin{array}{l}\text { Adamczyk e } \\
\text { Felson }\end{array}$ & 2012 & EUA & Empírico & NSYR & FM & $\begin{array}{l}\text { Modelo de regressão } \\
\text { logística multinomial }\end{array}$ & $2.530,13-17$ \\
\hline Eriksson et al. & 2013 & $\begin{array}{l}\text { África } \\
\text { do Sul }\end{array}$ & Empírico & Própria & FM & Grupo focal & $62,13-20$ \\
\hline Mbotho et al. & 2013 & $\begin{array}{l}\text { África } \\
\text { do Sul }\end{array}$ & Empírico & Própria & FM & $\begin{array}{l}\text { Entrevista em } \\
\text { profundidade }\end{array}$ & $19,16-24$ \\
\hline $\begin{array}{l}\text { Rosenbaum e } \\
\text { Weathersbee }\end{array}$ & 2013 & EUA & Empírico & Própria & FM & Wilcox, teste de associaç & $151(n$ \\
\hline
\end{tabular}

Fonte: Banco de Teses e Dissertações da UFMG e Cedeplar, SciELO, JSTOR e Atla. Revisão Bibliográfica Sistemática.

Notas: (n.a.) Não se aplica (1) Austrália, Áustria, Alemanha oriental e ocidental, Hungria, Irlanda, Itália, Israel, Holanda, Nova Zelândia,

Irlanda do Norte, Noruega, Filipinas, Polônia, Rússia, Eslovênia, Estados Unidos (2) Cross-sectional. W1= Wave 1, W2= Wave 2, W3=Wave 3.

(F) Feminino (M) Masculino (FM) Feminino e Masculino

\section{Descrição dos textos encontrados na RBS}

A revisão bibliográfica sistemática revelou que, em mais de meio século de pesquisas (1960-2013), muito já foi feito no sentido de procurar maneiras de medir a influência da religião e da religiosidade na iniciação sexual. A maior parte dos estudos encontrados nessa revisão foi feita nos Estados Unidos, o que pode ser reflexo da escolha dos bancos de dados pesquisados na revisão, que contêm muitos periódicos editados naquele país. Esse fato também pode ter refletido no grande número de estudos (90\%) com caráter empírico.

Com relação ao ano de publicação, o primeiro artigo é de 1960, enquanto o mais atual data de 2013. É interessante notar que, de 71 artigos pesquisados, quase dois terços foram publicados a partir de 2000, sugerindo um forte crescimento da religião como variável de interesse em pesquisas sobre a iniciação sexual, ou ainda um aumento do número de publicações científicas. O primeiro trabalho com este enfoque no Brasil foi realizado por Gupta (2000), com adolescentes residentes na Região Nordeste.

Percebeu-se que tanto mulheres quanto homens foram pesquisados, dependendo da disponibilidade dessa variável na base de dados utilizada, ou do desenho da amostra, quando a coleta de dados foi feita pelos próprios autores. Algumas bases de dados destacam-se pela grande quantidade de artigos publicados utilizando seus dados, como a National Survey of Family Growth (NFSG) (BILLY et al., 1994; COOKSEY et al., 1996; BREWSTER et al., 1998; MANLOVE et al., 2006; HAGLUND; FEHRING, 2010), a National Longitudinal Study of Adolescent Health (Add Health) (BEARMAN; BRÜCKNER, 2001; MEIER, 2003; ROSTOSKY et al., 2003; REGNERUS; SMITH, 2005; FRANCIS, 2007; MENNING et al., 2007) e as DHS - Demographic Health Surveys (GUPTA, 2000; ADDAI, 2000; LONGO, 2001; ISHIDA; STUPP; McDONALD, 2011), que, embora sejam mais limitadas em termos de informação sobre religião, têm boa amostragem e intervalos decenais.

Com relação à metodologia e aos métodos empregados nas análises dos artigos, percebe-se que, nas duas primeiras décadas, houve predominância da estatística quantitativa descritiva simples, sem testes de significância. Com o tempo, houve 
incremento e diversificação de métodos. A metodologia qualitativa só aparece a partir do final da década de 1990, com Fehring et al. (1998).

O tamanho amostral variou conforme a base de dados utilizada, a técnica de coleta de dados e as variáveis de interesse na pesquisa. Nem os autores que trabalhavam com as mesmas rodadas da mesma base de dados tiveram amostras idênticas, visto que a exclusão ou inclusão de uma variável é suficiente para alterar o número de casos válidos. A faixa etária pesquisada também variou, sendo que alguns entrevistaram jovens adultos e adultos com relação à primeira experiência sexual, dado que, para muitas realidades, o interesse é pesquisar a relação sexual pré-marital, que muitas vezes, mas não exclusivamente, acontece pela primeira vez na adolescência.

Por último, a decisão inicial de pesquisar literatura científica estrangeira foi acertada, haja vista que somente 12 textos investigaram a realidade brasileira (16\% do total).

\section{Classificações encontradas na RBS para religião e religiosidade}

Independente da forma como foram descritas, religião e religiosidade permaneceram, ao longo dos estudos, como variáveis associadas à iniciação sexual. Apesar de os métodos de análise terem se diversificado ao longo do tempo, percebe-se que a sofisticação das técnicas de categorização das respostas só foi possível após a criação de questionários específicos, nos quais haveria espaço para mensurar a religiosidade e a filiação religiosa com mais detalhamento do que a simples pergunta sobre denominação religiosa e frequência a cultos e celebrações. Dessa forma, as variáveis multidimensionais aumentaram a sensibilidade em relação a algumas características que diferenciam pessoas mais religiosas das menos religiosas.

É importante dizer que, ao se traduzirem os termos em inglês, muito da diversidade lexical utilizada no inglês para descrever a frequência de ida à igreja (church attendance, religious service attendance, frequency of service, religious participation) foi perdida, já que optou-se por nomeá-las como frequência de participação ou ida a igrejas ou cultos. Apesar da diminuição da variedade de vocabulário, a tradução procurou ser a mais literal possível, não alterando o sentido das sentenças, com exceção das categorias mainline protestants, que no Brasil referem-se aos protestantes históricos ou evangélicos de missão, e os institutional sects, que no caso brasileiro seriam como subdivisões das igrejas pentecostais.

\section{Formas de se classificar denominação/filiação religiosa}

Com base nas análises das metodologias dos artigos pesquisados na revisão bibliográfica, percebe-se que existem duas formas de se inserir a denominação religiosa nas análises quantitativas: a unidimensional e a multidimensional (Quadro 2). 
QUADRO 2

Formas de se classificar denominação/filiação religiosa

\begin{tabular}{|c|c|c|}
\hline & Autores & Categorias de resposta \\
\hline & Henze e Hudson (1974); França (2008) & Católicas; protestantes históricas; pentecostais; outras; nenhuma \\
\hline & Garner (2000) & $\begin{array}{l}\text { Pessoas que se recusaram a responder; católicas; protestantes; } \\
\text { outras; nenhuma }\end{array}$ \\
\hline & Paiva et al. (2008) & $\begin{array}{l}\text { Católicas; protestantes históricas; pentecostais e carismáticos; } \\
\text { espíritas kardecistas; afro-brasileiras; outras; nenhuma }\end{array}$ \\
\hline & Ogland et al. (2010) & $\begin{array}{l}\text { Catolicismo; Pentecostalismo; protestante tradicional (outra } \\
\text { protestante não pentecostal); espiritismo; religiões afro-brasileiras; } \\
\text { outra; sem religião }\end{array}$ \\
\hline & $\begin{array}{l}\text { Barbosa e Koyama (2008); Tanfer e } \\
\text { Horn (1985); Davis e Lay-Lee (1999); } \\
\text { Scheepers et al. (2002); Casper (1990) }\end{array}$ & Católicas; protestantes; outras; nenhuma \\
\hline & Landis (1960) & Católicas; protestantes; judia; nenhuma \\
\hline & Haglund e Fehring (2010) & Protestante; católico romano; sem religião; outra não cristã \\
\hline & Cooksey et al. (1996) & Católicas; protestantes fundamentalistas (1); outras \\
\hline$\underset{\tilde{0}}{\overline{0}}$ & Thornton e Camburn (1987) & $\begin{array}{l}\text { Católicas; protestantes não fundamentalistas (1); protestantes } \\
\text { fundamentalistas (1); outras }\end{array}$ \\
\hline$\overline{\bar{n}}$ & Hammond et al. (1993) & $\begin{array}{l}\text { Católicas; protestantes históricas; fundamentalistas (1); seitas; não } \\
\text { cristãs; nenhuma }\end{array}$ \\
\hline 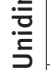 & Addai (2000) & $\begin{array}{l}\text { Católicas; protestantes; outras cristãs; muçulmana; tradicionais } \\
\text { (pagãs e de Deus “pequenos”); nenhuma }\end{array}$ \\
\hline & Slap et al. (2003) & Cristãs; muçulmana; outra; nenhuma \\
\hline & Odimegwu (2005) & Cristão ortodoxo; pentecostal; muçulmano; outras \\
\hline & Gupta (2000); Longo (2001) & Católica e não católica \\
\hline & Baptista (2011) & Católico; outra; nenhuma \\
\hline & Burchardt (2011) & Cristão; pentecostalismo e neotradicionalista \\
\hline & Miller et al. (1987) & Mórmons e não mórmons \\
\hline & Tavares et al. (2009) & Católica e outras (evangélicas; espíritas e outras) \\
\hline & Crawford et al. (2011) & $\begin{array}{l}\text { Pentecostal; Metodista; Igreja de Deus; Batista; católico; anglicano; } \\
\text { mórmon; adventista do sétimo dia }\end{array}$ \\
\hline & Eriksson et al. (2013) & $\begin{array}{l}\text { Igreja Católica Romana; Igreja Evangélica Luterana no Sul da África } \\
\text { (ELCSA); Assembleias de Deus }\end{array}$ \\
\hline & Mbotho, Cilliers e Akintola (2013) & Cristãos pentecostais e carismáticos \\
\hline & Adamczyk e Felson (2012) & $\begin{array}{l}\text { Protestante tradicional (mainline); protestante conservador; } \\
\text { católico; adventista do sétimo dia; não religioso ou em dúvida; } \\
\text { outra religião }\end{array}$ \\
\hline & Murray (1978) & Católicos ortodoxos e liberais \\
\hline & Miller e Bingham (1989) & $\begin{array}{l}\text { Cristãos fundamentalistas; batistas e mórmons; protestantes não } \\
\text { batistas; católicos não fundamentalistas; judeus e outras }\end{array}$ \\
\hline & Brewster et al. (1998) & Católicos praticantes; católicos ocasionais; fundamentalistas; outras \\
\hline 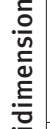 & Marsicano et al. (2011) & $\begin{array}{l}\text { Católicos praticantes regulares; católicos praticantes não regulares; } \\
\text { protestantes praticantes regulares; protestantes praticantes } \\
\text { não regulares; muçulmanos praticantes regulares; muçulmanos } \\
\text { praticantes não regulares; outra religião; sem religião }\end{array}$ \\
\hline$\stackrel{\bar{I}}{\underline{\underline{P}}}$ & Coutinho (2011) & $\begin{array}{l}\text { Católicos praticantes; católicos esporádicos; protestantes históricos } \\
\text { praticantes; protestantes históricos esporádicos; protestantes } \\
\text { pentecostais praticantes; protestantes pentecostais esporádicos; } \\
\text { protestantes; neopentecostais praticantes; protestantes } \\
\text { neopentecostais esporádicos; outras religiões; nenhuma religião }\end{array}$ \\
\hline & Regnerus e Smith (2005) & Protestante conservador e não protestante conservador \\
\hline
\end{tabular}

Fonte: Banco de Teses e Dissertações da UFMG e Cedeplar, SciELO, JSTOR e Atla. Revisão Bibliográfica Sistemática.

(1) "Fundamentalista" refere-se às categorias de filiação religiosa e não ao comportamento religioso. 


\section{Unidimensional}

A maneira mais simples de se classificar uma denominação ou filiação religiosa é a forma unidimensional, na qual a categoria de resposta corresponde exatamente à filiação religiosa relatada pelo respondente. Caso tenha sido coletada em questionário aberto, a classificação de religiões pode ser trabalhosa, haja vista a grande proporção de pessoas que, por desconhecerem o tipo de filiação religiosa, podem citar o nome da igreja frequentada (COUTINHO, 2011). A maioria dos artigos pesquisados que classificaram a religião de forma unidimensional, no entanto, já dispunha de categorias de resposta précodificadas nos questionários, que podem ser agrupadas de forma a facilitar a análise dos dados, como no caso dos participantes de igrejas metodistas e batistas que, muitas vezes, são agrupados em uma categoria maior denominada "protestantes históricos". Esse é o caso de diversos artigos pesquisados na revisão bibliográfica (Quadro 2), como Henze e Hudson (1974), Garner (2000), Barbosa e Koyama (2008), Haglund e Fehring (2010) e Crowford et al. (2011).

Dependendo do desenho da análise, ou do interesse da pesquisa, as categorias de resposta são agrupadas mais sinteticamente, transformando-se em categorias binárias. É o caso, por exemplo, de Gupta (2000) e Longo (2001), que classificaram a filiação religiosa de forma binária (católica ou não), assim como Miller et al. (1987) (mórmons ou não) e Mbotho, Cilliers e Akintola (2013) (cristãos pentecostais e carismáticos) (Quadro 2). Mais exemplos podem ser vistos no Quadro 2, que sumariza as diversas formas de classificação unidimensional de religião encontradas da RBS.

\section{Multimensional}

Uma maneira mais sofisticada de categorizar as denominações religiosas, mas que também depende da disponibilidade de dados, é aquela que cria categorias que não somente indicam a denominação religiosa per se, mas também acoplam uma outra característica que seja relevante ao estudo, como, por exemplo, a intensidade dessa religião, ou uma divisão interna, como no caso dos católicos, que podem ser mais conservadores ou liberais. Os exemplos encontrados na revisão bibliográfica se encontram no Quadro 2.

Murray (1978) separa a filiação religiosa católica - a única estudada - entre aqueles considerados ortodoxos e os liberais. Já Miller e Bingham (1989) agrupam filiação religiosa em uma categoria binária que não somente engloba as religiões, mas também as divide conforme sua posição contrária ou indiferente em relação ao sexo pré-marital. Assim, uma categoria é composta por "cristãos fundamentalistas", "batistas" e "mórmons”, que são considerados contra sexo pré-marital. Já a outra categoria é composta por "protestantes que não são batistas”, “católicos não fundamentalistas”, “judeus” e “outras religiões” (Quadro 2).

Coutinho (2011) e Marsicano et al. (2011) agrupam a frequência de participação aos cultos e celebrações à filiação religiosa. Eles possuem em comum as categorias católicos praticantes, católicos esporádicos, protestantes históricos praticantes, protestantes históricos 
esporádicos, protestantes pentecostais praticantes, protestantes pentecostais esporádicos, outras religiões e nenhuma religião. A diferença é que, enquanto no Brasil Coutinho inclui a categoria neopentecostal (protestantes, neopentecostais praticantes, protestantes neopentecostais esporádicos), Marsicano inclui a opção muçulmano (muçulmanos praticantes regulares, muçulmanos praticantes não regulares), já que seu trabalho é sobre a realidade francesa.

\section{Formas de se classificar a religiosidade}

Além das duas formas (unidimensional e multidimensional) de se classificarem as denominações religiosas, a categorização da religiosidade também fornece maior sofisticação, podendo exibir caráter uni e multidimensional. As diversas formas de classificação para religiosidade podem ser encontradas no Quadro 3.

QUADRO 3

Formas de se classificar a religiosidade

\begin{tabular}{|c|c|c|}
\hline & Autores & Categorias de resposta \\
\hline \multirow{8}{*}{ 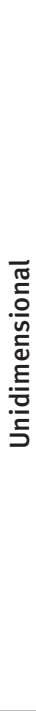 } & $\begin{array}{l}\text { Miller e Bingham (1989); } \\
\text { Slap et al. (2003) }\end{array}$ & Importância da religião na vida do respondente. \\
\hline & $\begin{array}{l}\text { Landis (1960); Miller e } \\
\text { Simon (1974) }\end{array}$ & $\begin{array}{l}\text { Muito devoto, devoto, pouco religioso, indiferente e antagonista no caso de } \\
\text { Landis (1960); muito religioso, um pouco religioso, não muito religioso e nada } \\
\text { religioso, no caso de Miller e Simon (1974). }\end{array}$ \\
\hline & Mahoney (1980) & Grau de religiosidade, sendo $0=$ nada intenso e $20=$ muito intenso. \\
\hline & Henze e Hudson (1974) & Se a mulher frequenta os cultos de sua religião. \\
\hline & Longo (2001) & Se vai à igreja ou ao culto pelo menos uma vez ao mês. \\
\hline & Hugo et al. (2011) & Se pratica religião \\
\hline & Gupta (2000) & $\begin{array}{l}\text { Se vai à igreja uma vez por mês ou mais; se vai à igreja poucas vezes ao ano ou } \\
\text { nunca. }\end{array}$ \\
\hline & $\begin{array}{l}\text { Miller et al. (1987); Jensen } \\
\text { et al. (1990); Hammond } \\
\text { et al. (1993); Davidson } \\
\text { et al. (1995); Murray et } \\
\text { al. (1998); Manlove et } \\
\text { al. (2006); Crawford et } \\
\text { al. (2011); Hennessy et } \\
\text { al. (2011); Ishida, Stupp } \\
\text { e McDonald (2011); } \\
\text { Rosenbaum e Weathersbee } \\
\text { (2013) }\end{array}$ & Frequência de ida aos serviços religiosos. \\
\hline \multirow[t]{3}{*}{ 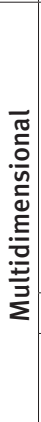 } & $\begin{array}{l}\text { Tanfer e Horn (1985); } \\
\text { Albrecht et al. (1977); } \\
\text { Kiragu e Zabin (1993); } \\
\text { Bearman e Brückner } \\
\text { (2001); Meier (2003); } \\
\text { Rostosky et al. (2003); } \\
\text { Regnerus e Smith (2005); } \\
\text { Odimegwu (2005); Francis } \\
\text { (2007); Haglund e Fehring } \\
\text { (2010) }\end{array}$ & $\begin{array}{l}\text { Frequência de ida à igreja (ou comunhão); importância pessoal da religião para } \\
\text { o jovem; frequência que reza ou ora; participação em grupo de jovem; leitura } \\
\text { diária da bíblia; pregação do evangelho; distribuição de material religioso; se se } \\
\text { importava com o que Deus pensa dele (1). }\end{array}$ \\
\hline & Burchardt (2011) & Observou padrões de frequência e reza. \\
\hline & Regnerus e Smith (2005) & $\begin{array}{l}\text { Escore médio de frequência de ida à igreja e importância da religião entre todos } \\
\text { os estudantes da escola; já ter "renascido" (born again) na primeira onda, ou } \\
\text { entre uma onda e outra. }\end{array}$ \\
\hline
\end{tabular}


(continuação)

\begin{tabular}{|c|c|c|}
\hline & Autores & Categorias de resposta \\
\hline & Fehring et al. (1998) & $\begin{array}{l}\text { Religiosidade foi medida com base em sete dos } 34 \text { itens utilizados na } \\
\text { Springfield Religiosity Survey (KOENIG et al., } 1988 \text { apud FEHRING et al., } 1998 \text {, } \\
\text { p. 233). As sete dimensões são: pensamento ortodoxo; ritual; experiência } \\
\text { religiosa; conhecimento religioso; bem-estar espiritual; religiosidade } \\
\text { comunitária; e religiosidade intrínseca. Esta última medida é baseada nas } \\
\text { respostas a dez quesitos da Intrinsic Religiosity Scale desenvolvida por } \\
\text { Hoge (1972 apud FEHRING et al., 1998, p. 233), sobre a importância que } \\
\text { o respondente dá para a fé: pensamentos ortodoxos; atividades religiosas } \\
\text { organizadas (frequência de idas às celebrações e atividades promovidas pela } \\
\text { igreja); suporte social religioso; e atividades religiosas não organizadas (como } \\
\text { orações, leitura da bíblia, etc.). }\end{array}$ \\
\hline & Rowatt e Schmitt (2003) & $\begin{array}{l}\text { Classificaram como orientação religiosa intrínseca aquelas pessoas que utilizam } \\
\text { a religião como um fim em si mesmo, por crescimento espiritual. Já as pessoas } \\
\text { com orientação religiosa extrínsecas são aquelas que utilizam a religião para } \\
\text { outra finalidade pessoal ou social. A definição do que era intrínseco e o que } \\
\text { era extrínseco foi feita com base nas Escalas de Orientação Religiosa propostas } \\
\text { por Allport e Ross's (1967) e Batson e Schoenrade's (1991) (apud ROWATT; } \\
\text { SCHMITT, 2003). }\end{array}$ \\
\hline & L’Engle et al. (2006) & $\begin{array}{l}\text { Variável de atitude religiosa foi medida utilizando a Intrinsic Religious } \\
\text { Motivation Scale, cujas categorias de resposta (variando entre um - discordo } \\
\text { fortemente - e cinco - concordo fortemente) eram aplicadas às frases: "minha } \\
\text { fé religiosa às vezes restringe minha ação"; "Nada é mais importante para } \\
\text { mim do que servir a Deus da melhor forma que eu puder"; e “Existem coisas } \\
\text { mais importantes na minha vida do que religião" (L'ENGLE et al., 2006, p. 100, } \\
\text { tradução nossa). Os itens foram somados e com eles foi criado um escore de } \\
\text { atitude religiosa. Já a frequência religiosa foi calculada com base em uma escala } \\
\text { que ia de um (nunca) a cinco (quatro ou mais vezes no mês). }\end{array}$ \\
\hline : & Woodroof (1985) & $\begin{array}{l}\text { Frequência aos cultos, frequência das rezas e preces pessoais, frequência } \\
\text { da leitura da bíblia, frequência à escola dominical, grau de envolvimento } \\
\text { na congregação, frequência com que faz contribuições financeiras para a } \\
\text { igreja, frequência com que conversa com outros jovens sobre as dificuldades } \\
\text { e alegrias da vida cristã, frequência com que conversa sobre religião com } \\
\text { amigos, familiares ou colegas, frequência com que tenta converter outras } \\
\text { pessoas, como se compara a importância do envolvimento religioso } \\
\text { do respondente hoje com o envolvimento que tinha antes de ir para a } \\
\text { universidade e se o envolvimento religioso do jovem cresceu ou diminuiu } \\
\text { desde que foi para a universidade. }\end{array}$ \\
\hline & Menning et al. (2007) & $\begin{array}{l}\text { Ter uma filiação religiosa, concordar que a sagrada escritura é a palavra literal } \\
\text { de Deus, frequência de ida aos serviços religiosos, importância da religião para } \\
\text { o respondente, frequência de reza e frequência de participação em atividades } \\
\text { religiosas para jovens. }\end{array}$ \\
\hline & Burdette e Hill (2009) & $\begin{array}{l}\text { Frequência de ida à igreja, religiosidade pessoal (denominada saliência religiosa } \\
\text { e medida por meio da religião e da fé na vida diária e nas decisões da vida), } \\
\text { religiosidade na esfera privada (quão frequente reza sozinho e quão frequente } \\
\text { lê a bíblia sozinho) e religiosidade familiar (se a família reza com frequência ou } \\
\text { agradece a Deus antes das refeições e com qual frequência a família fala sobre } \\
\text { Deus, as escrituras ou outras coisas espirituais ou religiosas) }\end{array}$ \\
\hline & Tulhofer (2011) & $\begin{array}{l}\text { Foi criado em ambiente religioso; religiosidade pessoal; tem medo dos } \\
\text { punimentos de Deus; fé ajuda a superar problemas e dificuldades da vida; } \\
\text { penso muito sobre fé, religião e Deus. }\end{array}$ \\
\hline & Adamczyk e Felson (2012) & $\begin{array}{l}\text { Tempo gasto em atividades organizadas por alguma instituição religiosa; } \\
\text { importância da religião; importância da fé na vivência da vida diária; } \\
\text { importância da fé ao influenciar decisões sobre coisas importantes na vida; } \\
\text { frequência de ida aos serviços religiosos; se respondente reza; se respondente } \\
\text { já se envolveu em grupo de jovens; frequência de ida aos serviços religiosos } \\
\text { pelos pais ou responsáveis do respondente. }\end{array}$ \\
\hline & Scheepers et al. (2002) & Frequência religiosa dos pais e religiosidade dos países. \\
\hline & Billy et al. (1994) & Frequência de ida à igreja ou aos cultos e religiosidade da comunidade. \\
\hline
\end{tabular}

Fonte: Banco de Teses e Dissertações da UFMG e Cedeplar, SciELO, JSTOR e Atla. Revisão Bibliográfica Sistemática. 


\section{Unidimensional}

Na forma unidimensional de classificação da religiosidade do respondente, apenas uma variável é considerada: geralmente, a frequência de participação nos cultos e celebrações religiosas, ou qualquer outra que o(a) pesquisador(a) julgar ser uma proxy adequada da religiosidade de uma pessoa. Esse é o caso de diversos artigos pesquisados na revisão bibliográfica (Quadro 3). Henze e Hudson (1974), Longo (2001), Gupta (2000) e Hugo et al. (2011) criaram variáveis dummies, sendo, respectivamente: se a mulher frequenta os cultos de sua religião; se vai à igreja ou ao culto pelo menos uma vez por mês; se vai à igreja pelo menos uma vez por mês, se vai à igreja poucas vezes por ano; se pratica religião. Outros, no entanto, utilizaram níveis de frequência de ida aos serviços religiosos, que variavam de mais que uma vez na semana até nunca (MILLER et al., 1987; JENSEN et al., 1990; HAMMOND et al., 1993; DAVIDSON et al., 1995; MURRAY et al., 1998; MANLOVE et al., 2006; CRAWFORD et al., 2011; HULL; HENNESSY, 2011; ISHIDA; STUPP; MCDONALD, 2011; ROSENBAUM; WEATHERSBEE, 2013).

Alguns autores deram ênfase à religiosidade individual autoavaliada, como foi o caso de Miller e Bingham (1989) e Slap et al. (2003), que a codificaram de acordo com a importância que a religião exerce sobre a vida da jovem: de baixa a alta, no caso de Miller e Binghan (1989); e muito importante, importante e não importante, no caso de Slap et al. (2003). Já Mahoney (1980) utilizou uma escala de 0 a 20, na qual o respondente deveria marcar seu grau de religiosidade, sendo 0 correspondente a nada intenso e 20 igual a muito intenso (Quadro 3).

\section{Multidimensional}

A revisão bibliográfica captou várias experiências de autores que utilizaram mais de uma variável para construir a variável religiosidade (Quadro 3), dando a ela um caráter multidimensional.

Em Tanfer e Horn (1985), Albrecht et al. (1977), Kiragu e Zabin (1993), Bearman e Brückner (2001), Meier (2003), Rostosky et al. (2003), Regnerus e Smith (2005), Odimegwu (2005), Francis (2007), Haglund e Fehring (2010) e Burchardt (2011), a religiosidade foi medida com base nas respostas às perguntas sobre frequência de ida à igreja (ou comunhão), importância pessoal da religião para o jovem (exceto ALBRECHT et al., 1977), frequência que reza ou ora (exceto TANFER; HORN, 1985; KIRAGU; ZABIN, 1993; REGNERUS; SMITH, 2005) ou outras variáveis pessoais do tipo participação em grupo de jovem (MEIER, 2003; FRANCIS, 2007), leitura da bíblia todos os dias, divulgação do evangelho, distribuição de material religioso e se a pessoa se importa com o que Deus pensa sobre ela (somente ODIMEGWU, 2005).

Escalas de resposta a diversas perguntas também foram utilizadas por autores como Woodroof (1985), Fehring et al. (1998), Scheepers et al. (2002), Rowatt e Schmitt (2003), L'Engle et al. (2006) e Burdette e Hill (2009). Para Woodroof (1985), por exemplo, a escala 
consistia em 11 perguntas sobre comportamento religioso, entre elas a frequência com que o respondente faz contribuições financeiras para a igreja e a frequência com que tenta converter outras pessoas. Para ter mais confiança no seu índice, a escala de Fehring et al. (1998) chegou a ser julgada por 158 líderes religiosos, que apontaram o que seria uma pessoa religiosa (KOENIG et al., 1988 apud FEHRING et al., 1998).

Saindo da escala de religiosidade do respondente, em Scheepers et al. (2002), a frequência religiosa dos pais foi relatada pelos estudantes e utilizada na pesquisa. Os autores também empregaram a religiosidade dos pais, que foi calculada com base em Kelley e De Graaf (1997 apud SCHEEPERS et al., 2002), que a consideraram uma média não ponderada da frequência religiosa dos pais e responsáveis na nação como um todo. As visões religiosas sobre o mundo foram calculadas com base nas respostas a perguntas sobre Deus e sua relação com as pessoas, o significado da vida e a existência de Deus. Billy et al. (1994) também adicionam à frequência de ida aos cultos e celebrações da igreja ou comunhão (católicos) uma variável que diz respeito à religiosidade da comunidade na qual estavam inseridos, por meio do cálculo da prevalência de pessoas consideradas religiosamente aderentes e religiosamente aderentes e conservadores.

\section{Resultados encontrados na RBS}

\section{Brasil}

Ao todo, 12 estudos encontrados pela revisão bibliográfica sistemática sobre iniciação sexual e religião ou religiosidade tiveram como foco o Brasil. Foram identificados cinco pontos principais, considerados não excludentes.

O primeiro ponto foi que a maior frequência religiosa, independentemente de filiação religiosa, estava relacionada com a menor iniciação sexual pré-marital (GUPTA, 2000; LONGO, 2001, COUTINHO, 2011; HUGO et al., 2011; BAPTISTA, 2011). Quanto mais alto o grau de religiosidade autoavaliado e mais elevada a religiosidade medida por meio da frequência aos serviços religiosos, menor é a chance de a iniciação sexual ter ocorrido.

Um segundo ponto encontrado foi que, com exceção de Baptista (2011), todos os outros estudos observaram correlações entre filiação religiosa e iniciação sexual, sendo que todas as categorias apresentaram chances reduzidas de o respondente já ter se iniciado sexualmente na época da entrevista, em comparação com a categoria de referência "nenhuma religião" (LONGO, 2001; FRANÇA, 2008; COUTINHO, 2011). Os que mais se aproximam de ter o mesmo risco de iniciação dos sem religião são os católicos, seguidos pelos neopentecostais (COUTINHO, 2011). Em seguida, para as mulheres, vêm as de outras religiões, as protestantes históricas e as pentecostais como o grupo mais conservador e, para os homens, os protestantes históricos, os pentecostais e os de outras religiões.

Um terceiro ponto encontrado na revisão é que a filiação religiosa aparenta estar relacionada com a opinião do jovem a respeito do sexo pré-marital ou na adolescência. Para os jovens evangélicos pentecostais, por exemplo, sexo só pode ser praticado dentro do 
casamento, ou seria considerado pecado ou “fornicação” (SILVA et al., 2008). Enquanto os sem religião são mais liberais, protestantes e pentecostais eram os que menos concordavam com as afirmações de que sexo é uma fonte de prazer, satisfação e uma necessidade física, como fome e sede. No entanto, o sexismo é forte, pois mais pessoas concordavam que mulheres (e não homens) devem esperar o casamento para iniciar a vida sexual (PAIVA et al., 2008).

No entanto, o quarto ponto verificado na revisão refere-se à existência de grande variabilidade no discurso dos jovens brasileiros. Paiva et al. (2008), utilizando a mesma base de dados de Barbosa e Koyama (2008), analisaram opiniões e atitudes diante da iniciação e educação sexual de adolescentes brasileiros, comparando respostas em 1998 e 2005. Os autores descobriram não haver um perfil bem delineado de adolescentes conservadores ou liberais, já que muitos dos que defendem abstinência até o casamento defendem também a educação sexual nas escolas e o crescimento da tolerância com relação ao sexo homossexual. Além disso, o grupo católico viveria a religiosidade sem participar dos rituais e sem se deixar levar pela moral católica vinda do Vaticano, a qual proíbe o sexo pré-marital e o uso de preservativo. Vidal e Ribeiro (2008), em um estudo qualitativo, também observaram a variedade de discursos dos jovens. Em resumo, os jovens entendem que existem discursos conflitantes na esfera da sexualidade, já que coexistem ideologias sexuais tradicionais e outras mais liberais. O resultado é fruto de uma “negociação entre as partes”, e não de uma impulsividade (NASCIMENTO; GOMES, 2009, p. 1106).

Um quinto ponto encontrado nessa revisão bibliográfica dos artigos brasileiros diz respeito à opinião das autoridades religiosas, que é, em geral, menos heterogênea e liberal do que a dos jovens. Rios et al. (2008) e Silva et al. (2008), em pesquisas qualitativas, investigaram o posicionamento de lideranças religiosas católicas e evangélicas sobre juventude e sexualidade. Segundo esses autores e os dados colhidos, tanto católicos quanto evangélicos criticam a erotização precoce que estimula a sexualidade juvenil e, apesar de reconhecerem as mudanças que a sociedade enfrentou na esfera da sexualidade, o atrelamento do sexo ao casamento ainda é uma preocupação dos líderes religiosos, já que sexo só deve ser feito após o jovem adquirir responsabilidade, entendida como consciência, maturidade afetiva, formação educacional, inserção no mercado laboral e matrimônio (RIOS et al., 2008). Assim, as igrejas têm que lançar mão de estratégias para assegurar que seus jovens não se engajem em atividades sexuais, como a ameaça da perda da posição de liderança ou do prestígio dentro da igreja. Há, também, uma valorização do jovem que espera, bem como a estigmatização daquele que desvia. "A estigmatização constitui estratégia importante para manter o rebanho sob controle” (RIOS et al., 2008, p. 681).

\section{Mundo}

Os estudos sobre outros países circulam em três eixos que, assim como no Brasil, não são excludentes. 0 primeiro eixo de estudos diz respeito à associação da denominação 
religiosa ou filiação religiosa à iniciação sexual. O sinal da relação tende a mudar conforme a orientação da religião. As mais permissivas costumam estar associadas com a iniciação sexual, enquanto as mais conservadoras tendem a agir no sentido de postergar o início da relação sexual. No entanto, há pouca consistência com relação aos resultados por filiação religiosa, haja vista que a religião que é considerada permissiva ou conservadora varia conforme a pesquisa, o país pesquisado e a época do estudo.

É interessante notar, a princípio, que a filiação católica, embora seja um grupo conservador, contra qualquer tipo de relação pré-marital, extramarital, incluindo uso de contracepção (BREWSTER et al., 1998, p. 496), tende a ser mais conservadora no exterior do que no Brasil (BRUNEAU, 1982 apud VERONA, 20107), onde apresenta grande variedade de crenças e práticas. Esse fato sugere que, apesar de os católicos serem regidos pelo Vaticano, a heterogeneidade dentro do grupo é grande. Enquanto Landis (1960) e Tavares et al. (2009), em épocas e países diferentes, descobriram que católicos iniciavam-se sexualmente mais cedo do que seus pares protestantes, outro grupo de pesquisadores verificou que católicos possuíam comportamento mais conservador e, por isso, iniciavam-se mais tarde do que o grupo de protestantes (CASPER, 1990; ODIMEGWU, 2005). No entanto, Marsicano et al. (2011), em um outro exemplo, mostram que, para católicos e protestantes, a frequência às cerimônias não os difere com relação à iniciação sexual.

Um achado quase universal é o fato de que pessoas sem religião tiveram mais chances de serem sexualmente iniciadas do que seus pares com alguma filiação religiosa (LANDIS, 1960; DAVIS; LAY-LEE, 1999; FRANCIS, 2007; TANFER; HORN, 1985). No entanto, Burdette e Hill (2009) esbarram em um resultado inusitado: não ter religião estava associado com menores chances de perda de virgindade no modelo completo. Uma das possíveis explicações é que adolescentes sem filiação podem estar mais expostos a mensagens de saúde pública, pois são menos ou nada protegidos dessas mensagens, as quais muitos pais e igrejas podem considerar contra os princípios religiosos (BURDETTE; HILL, 2009).

O segundo eixo de pesquisas, assim como no Brasil, busca associar a frequência de participação aos cultos e celebrações (frequência religiosa) e/ou a religiosidade do jovem com a iniciação sexual. Sem grandes variações nos resultados, a maior participação nos cultos e celebrações, assim como uma maior religiosidade, tende a estar associada com a postergação no início da atividade sexual (MILLER et al., 1987; WOODROOF, 1985; MILLER; SIMON, 1974; MANNING et al., 2007; SLAP et al., 2003; FEHRING et al., 1998; ALBRECHT et al., 1977; WOODROOF, 1985; ROSTOSKY et al., 2003; SCHEEPERS et al., 2002; FEHRING et al., 1998; ODIMEGWU, 2005; ISHIDA; STUPP; MCDONALD, 2011; ADAMCZYK; FELSON, 2012). Hull e Hennessy (2011), no entanto, observaram que os mais frequentes às cerimônias não se diferenciam dos que frequentam ocasionalmente, ou seja, ir à igreja de vez em quando já seria suficiente para que os efeitos da religião sobre a iniciação sexual fossem significantes. Em geral, os que se consideram mais religiosos também tendem a ter menores chances de

\footnotetext{
$\overline{7}$ Referência fora da RBS.
} 
iniciação sexual precoce (MEIER, 2003; MAHONEY, 1980; TANFER; HORN, 1985; LANDIS, 1960; FRANCIS, 2007; MILLER; BINGHAM, 1989; KIRAGU; ZABIN, 1993; ROSTOSKY et al., 2003; ROWATT; SCHMITT, 2003).

É importante notar que existe uma diferença entre religiosidade e religiosidade individual que, muitas vezes, é ignorada. Woodroof (1985) chama de intrinsically oriented aquele jovem que possui maior nível de religiosidade individual, como leitura de bíblia e rezas individuais, ao contrário dos extrinsically oriented. Ambos frequentam a igreja, mas a maior diferença entre eles é que o primeiro vê a religião como um fim em si e, por isso, a pratica, enquanto o segundo segue aquela religião como forma de obter algo mais, como contatos sociais. 0 autor conclui que existe uma relação entre virgindade e tipo de orientação religiosa: enquanto $86 \%$ dos intrinsically oriented eram virgens, apenas $62 \%$ dos extrinsically oriented não tinham se iniciado sexualmente na época da pesquisa. Rowatt e Schmitt (2003), em um estudo sobre orientação religiosa e experiências sexuais, descobriram que mulheres tendem a ser mais intrinsically oriented do que homens.

No estudo de Haglund e Fehring (2010), adolescentes que acreditavam que religião é importante tinham $27 \%$ menos chance de ter se iniciado sexualmente se comparados àqueles que não viam a religião como importante. Frequência a serviços religiosos diminuía a chance de iniciação para 46\%. A variável que mais importou foi “atitudes religiosas”, cujos jovens tinham 54\% da chance de ter se iniciado quando comparados com seus pares sem atitudes religiosas. Em Adamczyk (2012), o envolvimento em atividades seculares patrocinadas por entidades religiosas já era suficiente para diminuir a chance de a iniciação sexual ter ocorrido entre as ondas da pesquisa.

Por causa dessas diferenças, para Burdette e Hill (2009), a religiosidade que se manifesta no âmbito privado, ou a importância da religião para o jovem, pode ser melhor indicadora de religiosidade, especialmente em idades mais avançadas, já que o adolescente que frequenta cultos e cerimônias o faz porque assim deseja, e não porque foi obrigado, como seria o caso de crianças ou adolescentes mais novos, que são "carregados" para os cultos por suas famílias. No estudo de Mbotho, Silliers e Akintola (2013), por exemplo, o fator mais importante do adiamento da iniciação sexual foi "para agradar a Deus".

Além de a religiosidade e a frequência de participação aos cultos e celebrações do próprio jovem terem impacto sobre sua iniciação sexual, outras variáveis estiveram presentes nos estudos, como a religiosidade da família e da comunidade - quanto mais religiosas, menores as chances de o jovem ter se engajado em atividades sexuais ou possuir opiniões mais liberais (SCHEEPERS et al., 2002; BURDETTE; HILL, 2009; STULHOFER, 2011). Segundo os autores, isso é sinal de que adolescentes podem ser influenciados pela comunidade onde vivem, mas também que os custos psicológicos de engajar em atividades sexuais em comunidades muito religiosas podem ser altos. Resumindo, tanto a religiosidade individual, seja ela intrínseca ou extrínseca, quanto a religiosidade da família e da comunidade estão associadas à iniciação sexual. 
O terceiro eixo das pesquisas internacionais diz respeito à associação da filiação religiosa ou religiosidade com o grau de permissividade de contatos íntimos sexuais e/ou a opinião e a atitude sobre sexo pré-marital ou na adolescência. A permissividade anda junto com a iniciação sexual, obedecendo quase às mesmas associações, podendo se diferenciar dentro das filiações religiosas, geralmente em função do grau de conservadorismo de cada divisão religiosa da mesma filiação (MURRAY, 1978; JENSEN et al., 1990; FEHRING et al., 1998; GARNER, 2000). Apesar de ir contra a literatura, os autores encontram que a permissividade também estava correlacionada com pessoas que iam à igreja toda semana (JENSEN et al., 1990). Nesse caso, a hipótese dos autores é de que essas pessoas frequentam a igreja por conformidade social, e não por motivos religiosos. Mais uma vez, há a indicação de que variáveis de religiosidade individual, ao contrário de variáveis de frequência, podem captar melhor o verdadeiro efeito da religiosidade sobre a iniciação sexual.

\section{Considerações para estudos sobre religião e sexualidade}

A revisão bibliográfica também foi utilizada para entender e salientar alguns aspectos metodológicos relevantes, os quais deveriam ser levados em conta na ocasião de uma pesquisa sobre sexualidade e religião, não exclusivamente as realizadas com adolescentes.

O primeiro tópico a ser abordado é a definição dos conceitos de religião e religiosidade, bem como a interpretação e consistência com relação a esses significados ao longo da pesquisa e entre os entrevistados. Religião pressupõe um conjunto de crenças, rituais e códigos morais que são compartilhados por seus seguidores. Subentende-se que as diferentes denominações estarão relacionadas com diferentes normas e expectativas que contribuem para a formação e a prática do comportamento, incluindo a iniciação sexual (THORNTON; CAMBURN, 1989). Sendo dada a uma pessoa geralmente ainda na infância, a denominação religiosa poderia, então, por meio dos seus valores, normas e ensinamentos, definir ou ajudar a definir um comportamento (THORNTON; CAMBURN, 1989).

No entanto, ser católico no Brasil é diferente de ser católico em outros lugares; além disso, mesmo para pessoas nascidas e iniciadas nessa religião no mesmo país, a relação que a pessoa exerce com a religião poderá ser ou não definidora da sua denominação. Por exemplo, uma pessoa que foi batizada e nunca mais voltou à igreja pode querer dizer que é católica, ao passo que uma pessoa batizada que vai à igreja somente para assistir casamentos poderá dizer que não é. Essa limitação também acontece com a religiosidade: enquanto ir à igreja com alguma frequência, para um católico, já é considerado ser praticante (entre os mandamentos da igreja, está o de ir à igreja aos domingos e dias santos), para um evangélico, no entanto, o esperado é que se vá com a maior frequência possível (ROPER, 2007). Similarmente, um jovem criado em uma casa ou em uma comunidade onde o nível de engajamento religioso pessoal, como leitura de bíblia, é diário, pode se declarar menos religioso caso não leia a bíblia todos os dias (BILLY et al., 1994; SCHEEPERS et al., 2002). 
Diante dessas questões, comparações sobre quem é mais praticante devem ser feitas com cautela e, sempre que possível, outras medidas de religiosidade devem ser incorporadas à análise. Também se fazem necessárias medidas que categorizem religião e religiosidade da forma padronizada. Em vez de utilizar escalas de religiosidade (pouco, médio ou muito), são preferíveis medidas que controlem o que está sendo chamado de religiosidade - como, por exemplo, ler a bíblia todos os dias ou pregar o evangelho pelas ruas. Além disso, a religiosidade medida no âmbito privado (orações, leitura de bíblia) pode ser melhor indicadora de religiosidade, especialmente no final da adolescência quando o adolescente que pratica atividades ligadas à religiosidade o faz porque deseja, e não porque foi levado pelos pais (BURDETTE; HILL, 2009).

Um segundo fator importante mapeado pela RBS, já na esfera dos estudos de sexualidade em geral, é a qualidade das respostas. É preciso confiar na precisão das respostas, e quanto mais tempo tiver transcorrido entre o acontecimento (relação sexual) e o relato (entrevista), maiores são as chances de a data e as circunstâncias em que o evento aconteceu sumirem da memória (MILLER; SIMON, 1974). Entrevistar adolescentes e jovens adultos faz com que a qualidade da informação seja maior, já que o tempo transcorrido entre o evento e a entrevista é menor. No entanto, encontra-se o problema da conformidade social, quando os jovens podem tender a exagerar suas experiências como parte de uma ideologia dominadora que valoriza a virilidade masculina (HEILBORN; CABRAL, 2006), ou caminhem pelo lado inverso e escondam a verdade por medo, vergonha, ou ainda para manter os papéis de gêneros socialmente construídos, nos quais as mulheres devem fazer papel de virgens. Para tentar reduzir ao máximo a chance de um jovem exagerar ou esconder informação, principalmente por medo de ser identificado ou por vergonha do entrevistador, a tecnologia tem tido papel importante. Na pesquisa Add Health, os questionários aplicados no domicílio utilizavam uma tecnologia chamada audio-enhanced, computer-assisted self-interviewing (audio-CASI), que permitia que o aluno escutasse as perguntas em um headphone individual e as respondesse diretamente em um laptop (ROSTOSKY et al., 2003).

Uma terceira consideração nos estudos sobre sexualidade é pensar que o sexo, na forma de relação sexual vaginal, é a única forma de definir perda da virgindade ou início da vulnerabilidade a doenças e gravidezes indesejadas. Como bem notaram Borges e Schor (2007), antes da primeira relação sexual, os jovens podem engajar em outras experiências sexuais. Para as autoras, essas experiências merecem ser pesquisadas a fundo, dada sua relevância para a vulnerabilidade dos jovens, que muitas vezes são deixados à margem de serviços de saúde e discussões sobre prevenção por nunca terem tido relação sexual com penetração, apesar de já esboçarem comportamentos de risco. Além disso, segundo as autoras, o fato de a adolescência não ser uma fase homogênea, com trajetórias bem demarcadas, traz à baila a necessidade de se discutirem os múltiplos processos pelos quais o jovem caminha pela sexualidade, não tendo apenas a primeira vez como variável de interesse.

Um quarto ponto importante está relacionado à declaração sobre o grau de permissividade dos pais relatado pelos filhos. Segundo Thornton e Camburn (1987), crianças com atitudes 
e comportamentos mais permissivos tendem a pensar que seus pais também são mais permissivos, a fim de justificar o seu comportamento. Além disso, por exemplo, pode ser que a rigidez familiar não seja a definidora do status sexual do filho, mas sim o contrário. Para alguns jovens com comportamento muito liberal para o sexo, talvez seja necessário que a família se faça mais presente, tornando mais rígidas as regras de comportamento (KIRAGU; ZABIN, 1993).

Uma quinta consideração é a possibilidade de sexo não consentido, ou feito sob coerção, que pode acontecer com meninas e meninos de todas as religiões. Após a violência sexual, as pessoas podem reportar que já fizeram sexo, contribuindo para o aumento das estatísticas de sexualmente iniciados, quando, na verdade, elas são vítimas (BROWNE; FINKELHOR, 1986; BEITCHMAN et al., 1992 apud REYNOLDS, 1994).

A sexta consideração relevante diz respeito à amostra. Muitos dos estudos são feitos utilizando amostras muito localizadas ou de conveniência, que impedem que os achados sejam generalizados para a população total (BREWSTER et al., 1998). É preciso atenção na interpretação e generalização dos achados científicos, especialmente em se tratando de uma variável cultural como religião, que pode ter seu significado alterado conforme o contexto.

O sétimo e último problema metodológico a ser enfrentado é com relação à ordem dos acontecimentos, o que pode levar a conclusões precipitadas sobre o efeito de religião. Quatro situações são comumente descritas na literatura e devem ser consideradas, especialmente em caso de estudos do tipo cross-section.

A primeira situação é o fato de que a conversão religiosa pode ter acontecido após o início da vida sexual, dando a impressão de que jovens muito religiosos se iniciaram sexualmente independentemente de sua fé (THORNTON; CAMBURN, 1989).

Similarmente, uma segunda situação é conhecida como causalidade reversa. Em vez de ser virgem por ser evangélico, por exemplo, o adolescente pode, simplesmente, ter optado por essa religião para ganhar respaldo em continuar com a sua virgindade "intacta" ou seu comportamento menos permissivo (BREWSTER et al., 1998).

Uma terceira situação é descrita por Meier (2003). Em uma pesquisa de caráter longitudinal, a autora descobriu que, para mulheres, ter tido relações sexuais aumentou o grau de permissividade para o ato sexual pré-marital. No entanto, sua pesquisa não conseguiu captar se a mudança no grau de permissividade é devido à maior exposição à informação sobre sexo, à medida que começaram a praticá-lo, ou à utilização do discurso permissivo como justificativa por ter tido relações sexuais em uma idade precoce. A autora chama essa mudança no grau de permissividade de "adaptação da atitude depois da primeira relação sexual”, que pode corroborar as análises enviesadas sobre motivação ou grau de desejo para com a primeira relação sexual, já que a pergunta "o quanto você queria ter tido relação sexual na ocasião da primeira vez” é respondida após o ocorrido (MEIER, 2003, p. 1047).

Uma quarta situação, descrita por Regnerus e Smith (2005), refere-se aos efeitos de seleção. Os autores apontam que muito do que é considerado efeito da religião pode, na verdade, ser reflexo de efeitos de seleção, vieses na pesquisa ou efeitos espúrios. 
Jovens com problemas de comportamento, por exemplo, vão menos à igreja. É preciso ser cauteloso, então, para não dizer que esses jovens possuem esse comportamento porque não vão à igreja, ou que os jovens com bom comportamento são assim porque estão sob influência da religiosidade. Dessa forma, para entender os efeitos de frequência religiosa no comportamento sexual, é necessário compreender os efeitos de interação com outras variáveis (JENSEN et al., 1990).

Apesar de atormentarem os pesquisadores, essas quatro situações não são exclusividade de pesquisas sobre religião, mas sim uma deficiência advinda do método e base empregados na análise. Estudos qualitativos e estudos quantitativos longitudinais podem lançar luz sobre esses questionamentos.

Como foi visto, diversas considerações metodológicas devem ser feitas antes de se dar início a uma pesquisa sobre sexualidade e religião/religiosidade, de preferência antes mesmo da instrumentação da coleta de dados. Apesar de ter sido uma tentativa de elencar as considerações mais relevantes, os tópicos anteriormente relacionados não esgotam as considerações metodológicas de tal tema de pesquisa, tampouco as descrevem com detalhes.

\section{Conclusão}

Ao que tudo indica, religião e religiosidade são variáveis culturais que, sempre que possível, devem ser inseridas em pesquisas de âmbito demográfico, já que sua influência no comportamento sexual, no que tange à iniciação sexual, foi percebida pela maioria dos artigos aqui pesquisados, sugerindo que outras possíveis relações podem se fazer presentes. É necessário, no entanto, cautela com a classificação do "ser religioso" e com as diversas formas de interpretação da denominação religiosa. Recomenda-se que futuros questionários, nas mais diversas áreas da demografia, tragam quesitos capazes de avaliar com fidelidade a religiosidade do indivíduo, assim como sua igreja e seu nível de envolvimento religioso, a fim de que se possa observar a interação dessas variáveis culturais com outras variáveis demográficas. O refinamento nas classificações das variáveis e o uso de interações entre elas devem ser priorizados até que testes estatísticos e o bom senso do pesquisador comprovem a necessidade de se agruparem variáveis e utilizá-las nas formas simples e unidimensionais.

Com relação ao impacto da religião e religiosidade na iniciação sexual, o pouco mais de meio século de pesquisas que investigaram a associação entre religião e iniciação sexual adolescente revela que a influência da religião parece ser mais forte naqueles jovens que são mais religiosos. No entanto, os artigos também revelam que os jovens se veem divididos entre pelo menos dois discursos normativos: o da comunidade religiosa e o do convívio social mais amplo, sendo esse segundo provedor das informações que se fazem disponíveis para a maioria da população, tais como discursos de educação em saúde sobre sexo e preservativos. Assim, cabe ao jovem ouvir os discursos, assimilá-los ou “colocá-los em tensão” (SILVA et al., 2008, p. 690). 
Se as realidades são muitas e muitos são os fatores que podem ter influência na primeira relação sexual, o enfrentamento da educação para a sexualidade deve abarcar essas diferenças (BORGES; SCHOR, 2005). Como sugere Silva et al. (2008, p. 691), "se valorizarmos o diálogo que o sujeito religioso articula entre os discursos sobre sexualidade que freqüentam seu cotidiano, buscando lidar com a tensão e o conflito entre tradição e modernidade no plano individual, no plano programático estaremos aprendendo o caminho para o diálogo com as comunidades das diferentes matrizes e suas concepções próprias de heteronomia moral religiosa".

\section{Referências}

ADAMCZYK, A.; FELSON, J. The effect of religion-supported programs on health-related behaviors in adolescence. Review of Religious Research, v. 54, n. 4, p. 469-497, 2012.

ADAMCZYK, A. Investigating the role of religion-supported secular programs for explaining initiation into first sex. Journal for the Scientific Study of Religion, v, 51, n. 2, p. 324-342, 2012.

ADDAI, I. Religious affiliation and sexual initiation among Ghanaian women. Review of Religious Research, v. 41, n. 3, p. 328-343, Mar. 2000.

AFRICAN JOURNAL OF REPRODUCTIVE HEALTH / LA REVUE AFRICAINE DE LA SANTÉ REPRODUCTIVE, v. 11, n. 3, p. 133-149, Dec. 2007.

ALBRECHT, S. L.; CHADWICK, B. A.; ALCORN, D. S. Religiosity and deviance: application of an attitudebehavior contingent consistency model. Journal for the Scientific Study of Religion, v. 16, n. 3 , p. 263-274.

ALVES, J. E. D.; BARROS, L. F. W.; CAVENAGHI, S. A dinâmica das filiações religiosas no Brasil entre 2000 e 2010: diversificação e processo de mudança de hegemonia. Rever - Revista de Estudos da Religião, v. 12, p. 145-174, 2012.

ALVES, J. E. D.; NOVELLINO, M. S. F. A dinâmica das filiações religiosas no Rio de Janeiro: 1991-2000. Um recorte por educação, cor, geração e gênero. In: PATARRA, N.; AJARA, C.; SOUTO, J. (Orgs.). 0 Rio de Janeiro continua sendo... Rio de Janeiro: Ence/IBGE, 2006, p. 275-307.

BARBOSA, R. M.; KOYAMA, M. A. H. Comportamento e práticas sexuais de homens e mulheres, Brasil 1998 e 2005. Revista de Saúde Pública, v. 42 (Supl. 1), p. 21-33, 2008.

BAPTISTA, C. J. Prevalência de fatores de risco e perfil de vulnerabilidade à gravidez e DST/HIV/ Aids: estudo com adolescentes de escolas públicas de Montes Claros - Minas Gerais, Brasil, 20082009. Dissertação (Mestrado). Belo Horizonte: Programa de Pós-Graduação em Ciências da Saúde: Infectologia e Medicina Tropical, Universidade Federal de Minas Gerais - UFMG, 2011.

BEARMAN, P. S.; BRÜCKNER, H. Promising the future: virginity pledges and first intercourse. The American Journal of Sociology, v. 106, n. 4, p. 859-912, Jan. 2001.

BEMFAM. Pesquisa Nacional sobre Demografia e Saúde. Rio de Janeiro: Bemfam, 1996.

BERQUÓ, E. S.; CAVENAGHI, S. M. Increasing adolescent and youth fertility in Brazil: a new trend or a one-time event? In: THE ANNUAL MEETING OF THE POPULATION ASSOCIATION OFAMERICA, Philadelphia, 2005. Anais... Pennsylvania: Population Association of America, 2005.

BILLY, J. O. G.; BREWSTER, K. L.; GRADY, W. R. Contextual effects on the sexual behavior of adolescent women. Journal of Marriage and Family, v. 56, n. 2, p. 387-404, May 1994.

BRANDÃO, C. R. B. Fronteira da fé - Alguns sistemas de sentido, crenças e religiões no Brasil de hoje. Estudos Avançados, v. 18, n. 52, p. 282, 2004 (Dossiê Religiões no Brasil). 
BRASIL. Ministério da Saúde. Pesquisa Nacional de Demografia e Saúde da Criança e da Mulher (PNDS). Brasília, 2006.

BREWSTER, K. L.; COOKSEY, E. C.; GUILKEY, D. K.; RINDFUSS, R. R. The changing impact of religion on the sexual and contraceptive behavior of adolescent women in the United States. Journal of Marriage and Family, v. 60, n. 2, p. 493-504, May 1998.

BURCHARDT, M. Challenging Pentecostal moralism: erotic geographies, religion and sexual practices among township youth in Cape Town. Culture, Health \& Sexuality, v. 13, n. 6, p. 669-683, 2011.

BURDETTE, A. M.; HILL, T. D. Religious involvement and transitions into adolescent sexual activities. Sociology of Religion, v. 70, n. 1, p. 28-48, 2009.

CAETANO, A. J. O declínio da fecundidade e suas implicações: uma introdução. In: CAETANO, A. J.; ALVES, J. E. D.; CORRÊA, S. (Orgs.). Dez anos do Cairo: tendências da fecundidade e direitos reprodutivos no Brasil. Campinas: Abep e UNFPA, 2004.

CAMARANO. A. A. Fecundidade e anticoncepção na população jovem. Jovens acontecendo nas trilhas das políticas públicas. Brasília, CNPD, v. 1, 1998, p. 109-33.

CASPER, L. M. Does family interaction prevent adolescent pregnancy? Family Planning Perspectives, v. 22, n. 3, p. 109-114, May-Jun. 1990.

CHESNUT, R. A. Born again in Brazil - The Pentecostal boom and the pathogens of poverty. New Brunswick, NJ: Rutgers University Press, 1997.

CRAWFORD, T. V.; RAWLINS, J. M.; MCGROWDER, D.; ADAMS, R. The church's response to sexual reproductive health issues among youths: Jamaica's experience. Journal of Religion and Health, v. 50, n. 1, p. 163-176, 2011.

COOKSEY, E. C.; RINDFUSS, R. R.; GUILKEY, D. K. The initiation of adolescent sexual and contraceptive behavior during changing times. Journal of Health and Social Behavior, v. 37, n. 1, p. 59-74, Mar. 1996.

COSTA, J. V.; MELLO, L. F.; OJIMA, R. Religion and fertility: understanding adolescence pregnancy and family religion. In: XXV IUSSP CONFERENCE. Tours, France, 2005. Disponível em: 〈http://iussp2005. princeton.edu/download.aspx?submissionld=51318>. Acesso em: 11 jan. 2011.

COUTINHO, R. Z. A carne é fraca: religião, religiosidade e iniciação sexual entre estudantes do ensino médio na Região Metropolitana de Belo Horizonte, 2008. Dissertação (Mestrado). Belo Horizonte: Centro de Desenvolvimento e Planejamento Regional - Cedeplar, UFMG, 2011.

DAVIDSON, J. K. S. R.; DARLING, C. A.; NORTON, L. Religiosity and the sexuality of women: sexual behavior and sexual satisfaction revisited. The Journal of Sex Research, v. 32, n. 3 p. 235-243, 1995.

DAVIS, P.; LAY-YEE, R. Early sex and its behavioral consequences in New Zealand. The Journal of Sex Research, v. 36, n. 2, p. 135-144, May 1999.

ERIKSSON, E.; LINDMARK, G.; AXEMO, P.; HADDAD, B.; AHLBERG, B. Faith, premarital sex and relationships: are church messages in accordance with the perceived realities of the youth? A qualitative study in KwaZulu-Natal, South Africa. Journal of Religion and Health, v. 52, n. 2, p. 454-466.

FEHRING, R. J.; CHEEVER, K. H.; GERMAN, K.; PHILPOT, C. Religiosity and sexual activity among older adolescents. Journal of Religion and Health, v. 37, n. 3, p. 229-247, 1998

FRANÇA, M. B. Fatores associados à iniciação sexual e reprodutiva na adolescência: um estudo para Belo Horizonte e Recife, 2002. Dissertação (Mestrado). Belo Horizonte: Centro de Desenvolvimento e Planejamento Regional - Cedeplar, UFMG, 2008.

FRANCIS, S. A. Implications of public and private aspects of religiosity for the sexual decisions of black and white adolescents. Journal of Youth Ministry, v. 5, n. 2, p 15-31, 2007. 
FRESTON, P. Brother votes for brother: the new politics of protestantism in Brazil. In: GARRARD-BURNETT, V.; STOLL, D. (Orgs.). Rethinking Protestantism in Latin America. Philadelphia: Temple University Press, 1993, p. 66-110.

GARNER, R. C. Safe sects? Dynamic religion and AIDS in South Africa. The Journal of Modern African Studies, v. 38, n. I, p. 41-69, 2000.

GAYDOS, L. M.; SMITH, A.; HOGUE, C.; BLEVINS, J. An emerging field in religion and reproductive health. Journal of Religion and Health, v. 49, n. 4, p. 473-484, 2010.

GLASS, J. C. JR. Premarital sexual standards among church youth leaders: an exploratory study. Journal for the Scientific Study of Religion, v. 11, n. 4, p 361-367, 1972.

GUPTA, N. Sexual initiation and contraceptive use among adolescent women in Northeast Brazil. Studies in Family Planning, v. 31, n. 3, p. 228-238, Sep. 2000.

HAGLUND, K. A.; FEHRING, R. The association of religiosity, sexual education, and parental factors with risky sexual behaviors among adolescents and young adults. Journal of Religion and Health, v. 49, n. 4, p. 460-472, 2010.

HAMMOND, J. A.; COLE, B. S.; BECK, S. H. Religious heritage and teenage marriage. Review of Religious Research, v. 35, n. 2, p. 117-133, Dec. 1993.

HEILBORN, M. L.; AQUINO, E. M. L.; KNAUTH, D. R.; BOZON, M. (Orgs.). 0 aprendizado da sexualidade: reprodução e trajetórias sociais de jovens brasileiros. Rio de Janeiro: Garamond, 2006.

HEILBORN, M. L.; CABRAL, C. S. Sexual practices in youth: analysis of lifetime sexual trajectory and last sexual intercourse. Cadernos de Saúde Pública, v. 22, n. 7, p. 1471-1481, jul. 2006.

HENZE, L. F.; HUDSON, J. W. Personal and family characteristics of cohabiting and noncohabiting college students. Journal of Marriage and Family, v. 36, n. 4, p. 722-727, Nov. 1974.

HUGO, T. D. de O. et al. Fatores associados à idade da primeira relação sexual em jovens: estudo de base populacional. Cadernos de Saúde Pública, v. 27, n. 11, nov. 2011.

HULL, S. J. et al. Identifying the causal pathways from religiosity to delayed adolescent sexual behavior. The Journal of Sex Research, v. 48, n. 6, p. 543-553.

IBGE - Instituto Brasileiro de Geografia e Estatística. Censo Demográfico 2010. Características gerais da população, religião e pessoas com deficiência. Rio de Janeiro: Ministério do Planejamento, Orçamento e Gestão, IBGE, 2010, p. 1-215.

ISHIDA, K. et al. Prevalence and correlates of sexual risk behaviors among Jamaican adolescents. International Perspectives on Sexual and Reproductive Health, v. 37, n. 1, p. 6-15, 2011.

JENSEN, L.; NEWELL, R. J.; HOLMAN, T. Sexual behavior, church attendance, and permissive beliefs among unmarried young men and women. Journal for the Scientific Study of Religion, v. 29, n. 1, p. 113-117, Mar. 1990.

KINSEY, A.; POMEROY, W.; MARTIN, C.; GEBHARD, P. Sexual behavior in the human female. Philadelphia: Saunders, 1953.

KIRAGU, K.; ZABIN, L. S. The correlates of premarital sexual activity among school-age adolescents in Kenya. International Family Planning Perspectives, v. 19, n. 3, p. 92-97, Sep. 1993.

LANDIS, J. T. Religiousness, family relationships, and family values in protestant, catholic, and jewish families. Marriage and family living, v. 22, n. 4, p. 341-347, Nov. 1960.

LEITE, I. C.; RODRIGUES, R. N.; FONSECA, M. C. Fatores associados com o comportamento sexual e reprodutivo entre adolescentes das regiões Sudeste e Nordeste do Brasil. Cadernos de Saúde Pública, v. 20, n. 2 , p. 474-481, 2004. 
L'ENGLE, K. L.; JACKSON, C.; BROWN, J. D. Early adolescents' cognitive susceptibility to initiating sexual intercourse. Perspectives on Sexual and Reproductive Health, v. 38, n. 2, p. 97-105, Jun. 2006.

LONGO, L. A. F. B. Prevenir ou remediar? Um estudo das práticas contraceptivas entre as mulheres de 15 a 24 anos no Brasil. Dissertação (Mestrado). Centro de Desenvolvimento e Planejamento Regional da UFMG, Cedeplar, Belo Horizonte, 2001.

MAHONEY, E. R. Religiosity and sexual behavior among heterosexual college students. The Journal of Sex Research, v. 16, n. 2, p. 97-113, May 1980.

MANLOVE, J.; TERRY-HUMEN, E.; IKRAMULLAH, E. Young teenagers and older sexual partners: correlates and consequences for males and females. Perspectives on Sexual and Reproductive Health, v. 38, n. 4, p. 197-207, Dec. 2006.

MARSICANO, Ã. L.; LYDIE, N. et al. Gender and migration: the sexual debut of Sub-Saharan African migrants in France. Population, v. 66, n. 2, p. 275-301, 2011.

MARIANO, R. Expansão pentecostal no Brasil: o caso da Igreja Universal. Estudos Avançados, v. 18, n. 52, p. 121-138, 2004.

MBOTHO, M., CILLIERS, M.; AKINTOLA, O. Sailing against the tide? Sustaining sexual abstinence among Christian youth in a university setting in South Africa. Journal of Religion and Health, v. 52, n. 1, p. 208-222, 2013.

MCKINNON, S.; MCNAMEE, C.; POTTER, J. E. Adolescent fertility, marriage, race and religion in Brazil. In: THE POPULATION ASSOCIATION OF AMERICA AMERICA ANNUAL MEETING, 2007. Disponível em: 〈http://paa2007.pr inceton.edu/download.aspx?submissionld=72108〉. Acesso em: 10 abr. 2009.

MCKINNON, S.; POTTER, J. E.; GARRARD-BURNETT, V. Adolescent fertility and religion in Rio de Janeiro, Brazil in the year 2000: the role of protestantism. Population Studies, v. 62, n.3, p. 289 303, 2008.

MEIER, A. M. Adolescents' transition to first intercourse, religiosity, and attitudes about sex. Social Forces, v. 81, v. 3, p. 1031-1052, Mar. 2003.

MENNING, C.; HOLTZMAN, M.; KAPINUS, C. Stepfather involvement and adolescents' disposition toward having sex. Perspectives on Sexual and Reproductive Health, v. 39, n. 2, p. 82-89, Jun. 2007.

MILLER, B. C.; BINGHAM, C. R. Family configuration in relation to the sexual behavior of female adolescents. Journal of Marriage and Family, v. 51, n. 2, p. 499-506, May 1989.

MILLER, B. C.; HIGGINSON, R.; MCCOY, J. K.; OLSON, T. D. Family configuration and adolescent sexual attitudes and behavior. Population and Environment, v. 9, n. 2, p. 111-123, Jun. 1987.

MILLER, P. Y.; SIMON, W. Adolescent sexual behavior: context and change. Social Problems, v. 22, n. 1, p. 58-76, Oct. 1974.

MIRANDA-RIBEIRO, P.; POTTER, J. E. Eu vacilei: the epidemics of teenage pregnancy at the end of the twentieth century in Brazil. In: IV CONGRESO DE LA ASOCIACIÓN LATINOAMERICANA DE POBLACIÓN. Anais... Havana, Cuba, 16-19 November 2010.

MURRAY, C. The moral and religious beliefs of catholic adolescents: scale development and structure. Journal for the Scientific Study of Religion, v. 17, n. 4, p. 439-447, 1978.

MURRAY, N. J.; ZABIN, L. S.; TOLEDO-DREVES, V.; LUENGO-CHARATH, X. Gender differences in factors influencing first intercourse among urban students in Chile. International Family Planning Perspectives, v. 24, n. 3, p. 139-144+152, Sep. 1998.

NASCIMENTO, E. F.; GOMES, R. Iniciação sexual masculina: conversas íntimas para fóruns privados. Ciência e Saúde Coletiva, v. 14, n. 4, p. 1101-1110, 2009. 
OGLAND, C.; THANKAM S. S.; BARTOWSKI, J. P. C.; XU, X. Religious influences on teenage childbearing among Brazilian female adolescents. Journal for the Scientific Study of Religion, v. 49, n. 4, p. 754760, 2010.

OGLAND, C.; XU, X.; BARTOWSKI, J. P.; OGLAND, E. G. The association of religion and virginity status among Brazilian adolescents. Journal of Adolescent Health, v. 48, n. 6. p. 651-653, 2011.

ODIMEGWU, C. Influence of religion on adolescent sexual attitudes and behaviour among Nigerian university students: affiliation or commitment? African Journal of Reproductive Health / La Revue Africaine de la Santé Reproductive, v. 9, n. 2, p. 125-140, Aug. 2005.

PAIVA, V.; ARANHA, F.; BASTOS, F. I. Opiniões e atitudes em relação à sexualidade: pesquisa de âmbito nacional, Brasil 2005. Revista de Saúde Pública, v. 42 (Supl. 1), p. 54-64, 2008.

REGNERUS, M. D.; SMITH, C. Selection effects in studies of religious influence. Review of Religious Research, v. 47, n. 1, p. 23-50, Sep. 2005.

REYNOLDS, D. I. Religious influence and premarital sexual experience: critical observations on the validity of a relationship. Journal for the Scientific Study of Religion, v. 33, n. 4, p. 382-387, Dec. 1994.

RIOS, L. F.; PAIVA, V.; MAKSUD, I.; OLIVEIRA, C.; CRUZ, C. M. S.; CRUZ, C. G.; JUNIOR, V. T.; PARKER, R. OS cuidados com a "carne" na socialização sexual dos jovens. Psicologia em Estudo, v. 13, n. 4, p. 673682, out./dez. 2008.

ROHDEN et al. Religião e iniciação sexual em jovens de camadas populares. In: HEILBORN, M. L.; DUARTE, L. F. D.; PEIXOTO, C.; BARROS, M.L. de (Orgs.). Sexualidade, família e ethos religioso. Rio de Janeiro: Garamond, 2005.

ROPER, C. O valor da frequência à igreja. Disponivel em: «http://www.scribd.com/doc/3009583/0Valor-da-Frequencia-a-|grejà. Acesso em: 11 jan. 2011.

ROSENBAUM, J. E.; WEATHERSBEE, B. True love waits: do Southern Baptists? Premarital sexual behavior among newly married Southern Baptist Sunday School students. Journal of Religion and Health, v. 52, n. 1, p. 263-275.

ROSTOSKY, S. S.; REGNERUS, M. D.; WRIGHT, M. L. C. Coital debut: the role of religiosity and sex attitudes in the add health survey. The Journal of Sex Research, v. 40, n. 4, p. 358-367, Nov. 2003.

ROWATT, W. C.; SCHMITT, D. P. Associations between religious orientation and varieties of sexual experience. Journal for the Scientific Study of Religion, v. 42, n. 3, p. 455-465, Sep. 2003.

SCHEEPERS, P.; GROTENHUIS, M. T.; SLIK, F. V. D. Education, religiosity and moral attitudes: explaining cross-national effect differences. Sociology of Religion, v. 63, n. 2, p. 157-176, 2002.

SHORNACK, L. L.; AHMED, F. Adolescent religiousness and pregnancy prevention: a comment on research by studer and thornton. Journal of Marriage and Family, v. 51, n. 4, p. 1083-1085, Nov. 1989.

SILVA, C. G.; SANTOS, A. O.; LICCIARDI, D. C.; PAIVA, V. Religiosidade, juventude e sexualidade entre a autonomia e a rigidez. Psicologia em Estudo, v. 13, n. 4, p. 683-692, out./dez. 2008.

SIMÃO, A. B.; MIRANDA-RIBEIRO, P.; CAETANO, A. J.; CÉSAR, C. C. Comparando as idades à primeira relação sexual, à primeira união e ao nascimento do primeiro filho de duas coortes de mulheres brancas e negras em Belo Horizonte: evidências quantitativas. Revista Brasileira de Estudos de População, v. 23, n. 1, p. 151-166, jan./jun. 2006.

SLAP, G. B.; LOT, L.; HUANG, B.; DANIYAM, C. A.; ZINK, T. M.; SUCCOP, P. A. Sexual behaviour of adolescents in Nigeria: cross sectional survey of secondary school students. British Medical Journal, v. 326, n. 7379, p. 15-18, Jan. 2003.

SMITH, C. Theorizing religious effects among American adolescents. Journal for the Scientific Study of Religion, v. 42, n. 1, p. 17-30, Mar. 2003. 
SMITH, D. J. Youth, sin and sex in Nigeria: Christianity and HIV/AIDS-related beliefs and behaviour among rural-urban migrants. Culture, Health e Sexuality, v. 6, n. 5, p. 425-437, Sep.-Oct. 2004.

SOUZA, M. M. C. A maternidade nas mulheres de 15-19 anos como desvantagem social. In: VIEIRA, E. M.; FERNANDES, M. E. L.; BAILEY, P. E.; MCKAY, A. (Orgs.). Seminário Gravidez na Adolescência. São Paulo: Associação Saúde da Família, 1998, p. 74-91.

SPANIER, G. B. Sexualization and premarital sexual behavior. The Family Coordinator, v. 24, n. 1, p. 33-41, Jan. 1975.

STEELE, L. G. A gift from God: adolescent motherhood and religion in Brazilian favelas. Sociology of Religion, v. 72, n. 1, p. 4-27, 2011.

STUDER, M.; THORNTON, A. The multifaceted impact of religiosity on adolescent sexual experience and contraceptive. A reply to shornack and Ahmed. Journal of Marriage and Family, v. 51, n. 4, p. 1085-1089, Nov. 1989

STULHOFER, A. D. Å et al. Religiosity and sexual risk behavior among Croatian college students, 19982008. The Journal of Sex Research, v. 48, n. 4, p. 360-371, 2011.

TANFER, K.; HORN, M. C. Contraceptive Use, pregnancy and fertility patterns among single American women in their 20s. Family Planning Perspectives, v. 17, n. 1, p. 10-19, Jan.-Feb. 1985.

TAVARES, C. M.; SCHOR, N.; JUNIOR, I. F.; DINIZ, S. G. Factors associated with sexual initiation and condom use among adolescents on Santiago Island, Cape Verde, West Africa. Cadernos de Saúde Pública, v. 25, n. 9, p. 1969-1980, set. 2009.

THORNTON, A. Reciprocal influences of family and religion in a changing world author. Journal of Marriage and Family, v. 47, n. 2, p. 381-394, May 1985.

THORNTON, A.; CAMBURN, D. The influence of the family on premarital sexual attitudes and behavior. Demography, v. 24, n. 3, p. 323-340, Aug. 1987.

THORNTON, A.; CAMBURN, D. Religious participation and adolescent sexual behaviors and attitudes. Journal of Marriage and the Family, n. 51, p. 641-653, 1989.

VERONA, A. P. A. Sexual initiation and religion in Brazil. Tese (Doutorado em Sociologia). University of Texas at Austin, 2010.

Explanations for religious influence on adolescent sexual behavior in Brazil: direct and indirect effects. Revista Brasileira de Estudos de População, v. 28, p. 187-201, 2011.

VERONA, A. P. A.; DIAS JÚNIOR, C. S. Religião e fecundidade entre adolescentes no Brasil. Revista Panamericana de Salud Pública / Pan American Journal of Public Health, v. 31, p. 25-31, 2012.

VIDAL, E. I.; RIBEIRO, P. R. M. Algumas reflexões sobre relacionamentos afetivos e relações sexuais na adolescência. Fractal: Revista de Psicologia, v. 20, n. 2, p. 519-532, jul./dez. 2008.

WHITEHEAD, B. D.; WILCOX, B. L. et al. Keeping the faith: the role of religion and faith communities in preventing teen pregnancy. Washington, DC: National Campaign to Prevent Teen Pregnancy, 2001.

WOODROOF, J. T. Premarital sex and religious adolescents. Journal for the Scientific Study of Religion, v. 24, n. 4, p 346-366, 1985. 


\section{Sobre as autoras}

Raquel Zanatta Coutinho é teaching fellow e aluna de doutorado em sociologia na University of North Carolina at Chapel Hill, nos Estados Unidos, e mestre em demografia pelo Centro de Desenvolvimento e Planejamento Regional da Universidade Federal de Minas Gerais (Cedeplar/ UFMG).

Paula Miranda-Ribeiro é doutora em sociologia pela University of Texas at Austin, Estados Unidos, e mestre em demografia pelo Cedeplar/UFMG. Bolsista de produtividade 1C do CNPq e professora associada do departamento de Demografia do Centro de Desenvolvimento e Planejamento Regional da Universidade Federal de Minas Gerais (Cedeplar/UFMG).

\section{Endereço para correspondência}

Raquel Zanatta Coutinho

University of North Carolina at Chapel Hill

155 Hamilton Hall, CB 3210

Chapel Hill, NC 27599, USA

\section{Abstract \\ Religion, religiosity and sexual initiation during adolescence: lessons from a systematic literature review of a half-century of research}

The influence of religion on sexuality has been under investigation by international researchers for nearly half a century. Religion as a variable with effects on sexual behavior has emerged in Brazilian literature as this society goes through two related sets of changes, to wit, the religious landscape and norms and values associated with sexuality. Given the growing interest in this latter demographic variable, studies are needed on which to base future research in Brazil. The present paper seeks to review the Brazilian and international literature on links among religion, religiosity and adolescent sexual initiation and to identify manners of classifying religion and religiosity. Methodological issues that should be taken into account in studies on adolescent sexuality and religion are also discussed briefly. The literature review tracks and analyzes articles published between 1950 and 2010 in Portuguese and English using the SciELO, Atla and JSTOR databases as well as master's theses and PhD dissertations from Cedeplar and theses and dissertations from UFMG (online database).

Keywords: Sexual initiation. Religion. Religiosity. Adolescence. Systematic literature review.

\section{Resumen}

Religión, religiosidad e iniciación sexual en la adolescencia y la juventud: lecciones de una revisión bibliográfica sistemática de más de medio siglo de investigación

Aunque no ha sido muy estudiada en Brasil, a nivel internacional la influencia de la religión sobre la sexualidad se ha investigado durante más de medio siglo. En la literatura brasileña, la religión como una variable de interés demográfico con impacto en el comportamiento sexual ha ido ganando importancia a medida que se producen cambios en el panorama religioso y las normas y los valores asociados a la sexualidad. Ante el creciente interés de los demógrafos por esta variable, se hacen necesarios más fundamentos teóricos para apoyar las futuras investigaciones y estudios brasileños en este campo. Este trabajo se propone entonces “mapear" la bibliografía nacional e internacional sobre 
la asociación entre religión, religiosidad e iniciación sexual de los adolescentes y los jóvenes y revelar las numerosas maneras utilizadas para clasificar la religión y la religiosidad en los últimos años. Este análisis también pretende resaltar los cuidados metodológicos que se deben tener en el estudio de la sexualidad adolescente y la religión en general. Para cumplir con estos dos objetivos se realizó una revisión sistemática de la bibliografía disponible en las bases de datos SciELO, Atla, JSTOR y el Banco de Tesis y Disertaciones del Centro de Desenvolvimento e Planejamento Regional (CEDEPLAR) y la Universidade Federal de Minas Gerais (UFMG), considerando artículos publicados entre 1950 y abril de 2014, tanto en portugués como en inglés.

Palabras clave: Iniciación sexual. Religión. Religiosidad. Adolescencia. Revisión bibliográfica sistemática.

Recebido para publicação em 30/07/2013

Aceito para publicação em 04/11/2014 
